\title{
Yin and Yang of Biofilm Formation and Cyclic di-GMP Signaling of the Gastrointestinal Pathogen Salmonella enterica Serovar Typhimurium
}

\author{
Agaristi Lamprokostopoulou ${ }^{a}$ Ute Römling ${ }^{b}$ \\ aCenter of Basic Research, Biomedical Research Foundation of the Academy of Athens, Athens, Greece; \\ ${ }^{b}$ Department of Microbiology, Tumor and Cell Biology, Karolinska Institutet, Stockholm, Sweden
}

\section{Keywords \\ Cyclic diguanylate monophosphate $\cdot$ Salmonella \\ Typhimurium · Biofilm formation · Virulence · Immune \\ response}

\begin{abstract}
Within the last 60 years, microbiological research has challenged many dogmas such as bacteria being unicellular microorganisms directed by nutrient sources; these investigations produced new dogmas such as cyclic diguanylate monophosphate (cyclic di-GMP) second messenger signaling as a ubiquitous regulator of the fundamental sessility/motility lifestyle switch on the single-cell level. Successive investigations have not yet challenged this view; however, the complexity of cyclic di-GMP as an intracellular bacterial signal, and, less explored, as an extracellular signaling molecule in combination with the conformational flexibility of the molecule, provides endless opportunities for cross-kingdom interactions. Cyclic di-GMP-directed microbial biofilms commonly stimulate the immune system on a lower level, whereas host-sensed cyclic di-GMP broadly stimulates the innate and adaptive immune responses. Furthermore, while the intracellular second messenger cyclic di-GMP signaling promotes bacterial biofilm formation and chronic infections,
\end{abstract}

oppositely, Salmonella Typhimurium cellulose biofilm inside immune cells is not endorsed. These observations only touch on the complexity of the interaction of biofilm microbial cells with its host. In this review, we describe the Yin and Yang interactive concepts of biofilm formation and cyclic di-GMP signaling using $\mathrm{S}$. Typhimurium as an example.

(c) 2021 The Author(s).

Published by S. Karger AG, Basel

\section{Introduction}

Regulation of virulence properties of a microbial organism and its interaction with a potential host is highly dependent on environmental conditions. As has been observed exemplarily by laboratory studies, plate-grown cells of the gastrointestinal pathogen Salmonella enterica serovar Typhimurium are hardly virulent, while liquidgrown $S$. Typhimurium cells readily invade host cells [1], a regulation occurring already at the transcriptional level [2]. Part of this delicate regulation between acute virulence and commensalism/chronic infection is executed by a small molecule whose local or global concentration responds readily to environmental conditions, namely the ubiquitous second messenger cyclic diguanylate monophosphate (cyclic di-GMP) [3-6]. Cyclic di-GMP is
C 2021 The Author(s).

Published by S. Karger AG, Basel

This article is licensed under the Creative Commons Attribution 4.0 International License (CC BY) (http://www.karger.com/Services/ OpenAccessLicense). Usage, derivative works and distribution are permitted provided that proper credit is given to the author and the original publisher.
Correspondence to:

Ute Römling, ute.romling@ki.se 
one, and perhaps, the most important member of a larger family of cyclic di- and oligonucleotide second messengers that primarily include the predominantly Gram-positive cyclic di-AMP and the hybrid molecule $3^{\prime} 3^{\prime}$-cyclic AMP-GMP [7, 8]. Recently, the discovery of a broad panel of additional cyclic di- and oligonucleotides has been substantialized including compounds previously only predictively chemically synthesized [9-14]. Cyclic oligonucleotide second messengers possess a major role in the regulation of the activity of nucleases in CRISPR/Casbased innate immune response against bacteriophages [14-16]. On an evolutionary scale, the metazoan viral defense cGAS-STING (cyclic GAMP synthase - stimulator of interferon genes) pathway with the $2^{\prime} 3^{\prime}$-cyclic GMPAMP analog as the second messenger has its foundation in microbial components $[13,17]$.

The spatial and temporal intracellular concentration of the second messenger cyclic di-GMP which occurs in over $75 \%$ of all bacterial species is adjusted on the singlecell level by a multitude of turnover proteins and receptors [18] and consequently delicately regulates a wide variety of physiological and metabolic traits that channel into acute versus chronic virulence, and sessility versus motility, as well as concomitantly in the promotion of antimicrobial and detergent tolerance and tolerance against the immune response. In this context, cyclic di-GMP can direct fundamental processes such as carbon source catabolism, respiration, cell division, and cell shape by affecting global molecular processes such as RNA turnover, proteolysis, protein acetylation, secretion, and the catalytic activity of biofilm matrix biosynthesis enzymes. This physiological and behavioral consequences have a wide impact not only in the clinical, industrial, and agricultural setting, but also shape the ecology in oceans and affect geochemical relevant global compounds and cycles, such as the denitrification cycle [19-23]. The conformational flexibility and the ability to form various types of oligomers and few amino acids sufficient to define binding make it challenging to predict the binding sites of cyclic di-GMP $[5,24]$.

Environmental and intrinsic signals received by cyclic di-GMP turnover proteins determine not only the (acute) virulence properties of microorganisms, but can also provoke the expression of different types of biofilms such as Pseudomonas aeruginosa biofilm formation in the urinary tract versus laboratory-grown biofilms [25]. The multitude of signals that direct the turnover activity of the cyclic di-GMP second messenger signaling system (equally as those of other second messengers and phosphotransfer signal transduction systems, chemotaxis systems, and other, which are discussed here in the context of relevant cross talk) on the transcriptional, post-transcriptional, and post-translational level integrates into a specific output response which is equally dependent on the receptor and target proteome status combined with the rest of the proteome [6]. The predominant extracellular matrix components that cover the bacterial cells in a honeycomb-like fashion include amyloid curli fimbriae and the exopolysaccharide cellulose. Curli and (phosphoethanolamine modified) cellulose possess clearly defined features, which point to opposite functionality [27-29]. In this mini-review, we discuss the Yin and Yang functionality of the extracellular matrix components, biofilm formation, biofilm regulators, and cyclic di-GMP signaling in bacterial and bacterial-host interactions taking mainly the gastrointestinal pathogen $S$. Typhimurium as an example (Fig. 1).

\section{Amyloid Curli Fimbriae and the Exopolysaccharide Cellulose as Opposing Extracellular Matrix Components of S. Typhimurium Biofilms}

A highly hydrophobic outer shell encloses cells of the plate-grown rdar (red, dry, and rough) morphotype of S. Typhimurium, Escherichia coli, and other enterobacteria upon expression of two major extracellular matrix components: amyloid curli fimbriae and the exopolysaccharide cellulose (Fig. 2; [30-32]). These two polymeric extracellular matrix components tightly interact to display a full biofilm phenotype (bacterial wood), but with each of these matrix components actually to possess a distinct and frequently opposite functionality (Fig. 2). The extracellularly polymerized amyloid curli with subunits characterized by 5 parallel pseudo-repetitive beta-strands converts the cell surface toward hydrophobicity with promiscuous adhesive properties toward proteins and surfaces (Fig. 2a; [31, 33-37]). Consequently, biofilm cells expressing curli fimbriae interact tightly with abiotic and biotic surfaces $[28,30]$. In contrast, expression of the exopolysaccharide cellulose leads to an overall hydrophilic cell surface as measured by the contact angle of bacterial macrocolonies [31]. Cellulose provides predominantly flexible cell-cell interactions in a static rich culture medium, while under continuous flow in minimal medium cellulose contributes to surface adherence and cell-cell interactions [31, 38-40]. Although the expression of these two matrix components is tightly coupled in plate-grown biofilms through direct and indirect regulation by the bistably expressed transcriptional regulator CsgD, the con- 


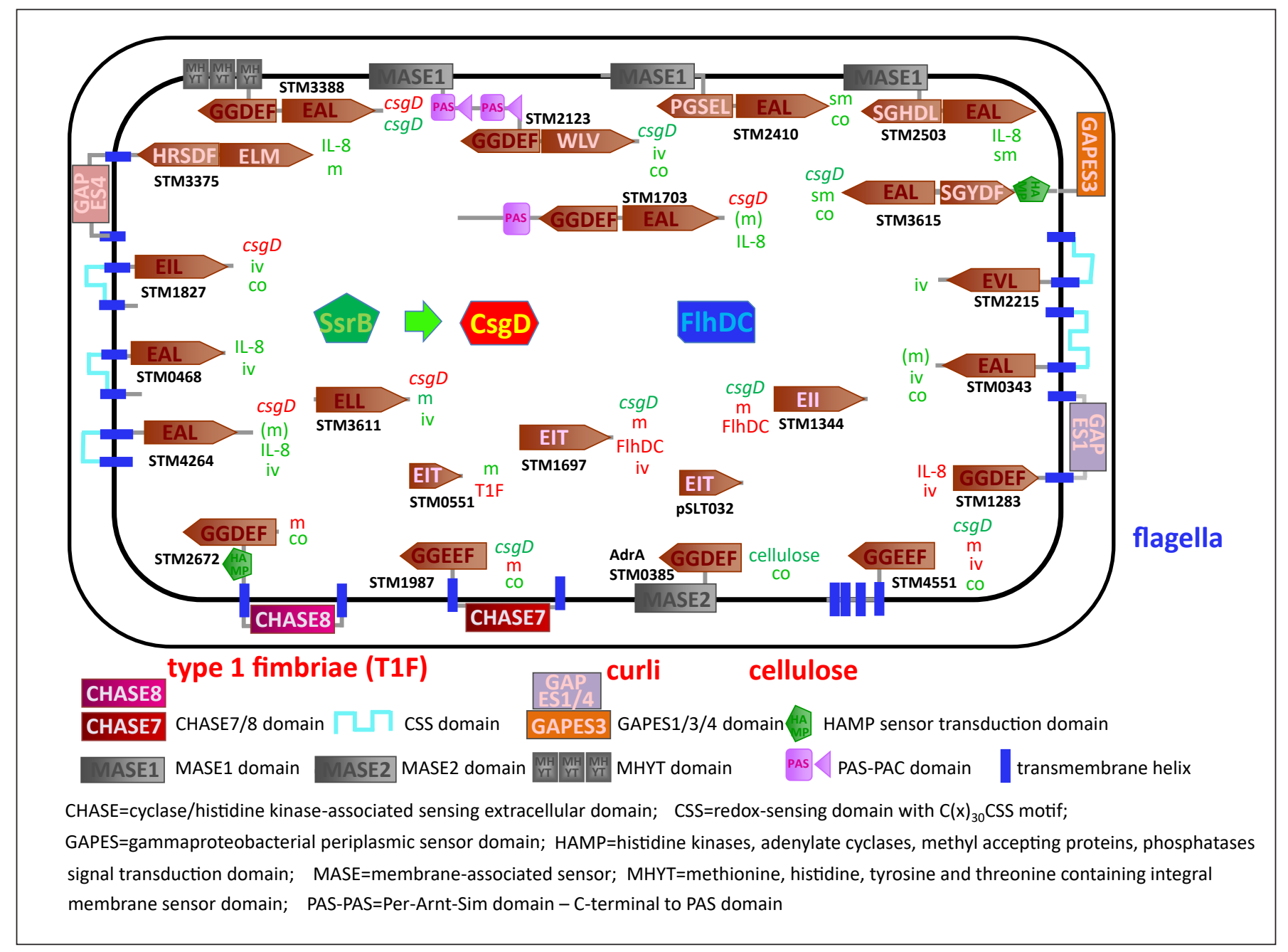

Fig. 1. The cyclic di-GMP signaling network of $S$. Typhimurium ATCC14028 and its effect on biofilm formation, motility, and virulence-related phenotypes. The genome of $S$. Typhimurium codes for 22 conserved and evolved cyclic di-GMP turnover proteins. The effect of a gene, as assessed upon deletion, on particular phenotypes $(\operatorname{csg} \mathrm{D}=$ production of the biofilm activator CsgD; cellulose = biosynthesis of the exopolysaccharide cellulose; $\mathrm{m}=$ apparent motility; FlhDC = inhibition of the class I flagellar regulon activator $\mathrm{FlhD}_{4} \mathrm{C}_{2} ;$ IL-8 = secretion of the proinflammatory cytokine IL- 8 by the epithelial cell line HT-29; iv = invasion of the intestinal cell line HT-29; sm = survival in macrophages; $\mathrm{co}=$ colonization of the gastrointestinal tract (as assessed by analysis of feces)) in the strain S. Typhimurium ATCC14028 is indicated; green

comitant expression can be uncoupled under alternative environmental conditions or even subsequent genetic alteration $[40,41]$. The distinct physicochemical characteristics of the extracellular biofilm matrix components curli and cellulose extend into distinct host-pathogen interactions as described below.

Virulence versus Biofilm of Salmonella

Typhimurium
$=$ promotion of phenotype; red $=$ suppressive effect on phenotype. In brackets, not consistently observed. The response regulator SsrB in its unphosphorylated form activates expression of the $\operatorname{cs} g D$ biofilm regulator gene; FlhDC = class I flagellar regulon activator $\mathrm{FlhD}_{4} \mathrm{C}_{2}$. Cyclic di-GMP, cyclic diguanylate monophosphate; CHASE, cyclase/histidine kinase-associated sensing extracellular domain; CSS, redox-sensing domain with $\mathrm{C}(\mathrm{x})_{30-}$ CSS motif; GAPES, gammaproteobacterial periplasmic sensor domain; HAMP, histidine kinases, adenylate cyclases, methyl-accepting proteins, phosphatases signal transduction domain; MASE, membrane-associated sensor; MHYT, methionine, histidine, tyrosine, threonine containing integral membrane sensor domain; PASPAC, Per-Arnt-Sim domain - C-terminal to PAS domain.

\section{The Cyclic di-Nucleotide Second Messenger Signaling System}

The universally conserved predominantly bacterial secondary messenger cyclic di-GMP was initially identified in the bacterium Komagataeibacter xylinus (orig- 


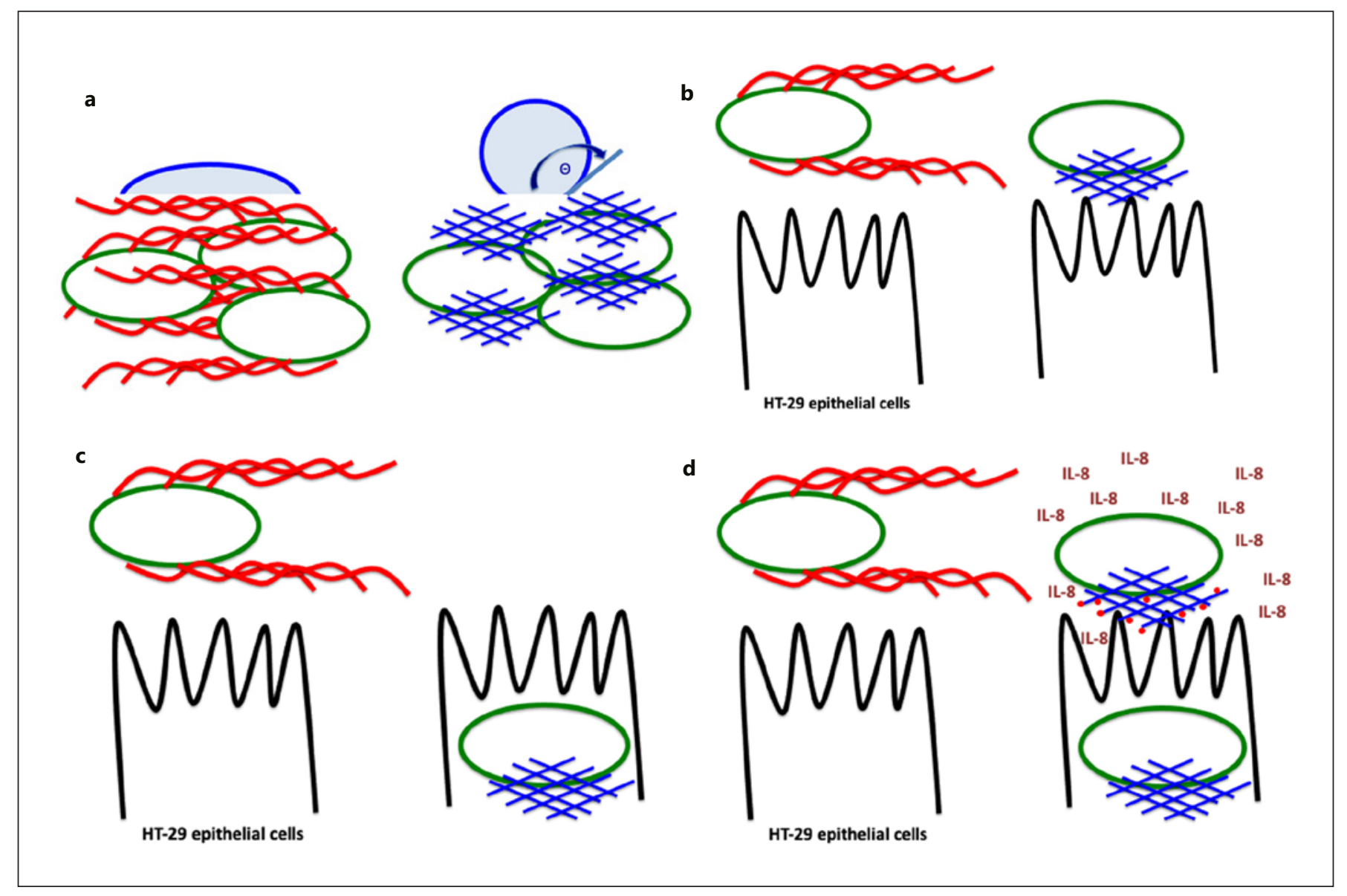

Fig. 2. The extracellular matrix components of the rdar biofilm, the exopolysaccharide cellulose, and amyloid curli fimbriae possess distinct features and furnish $S$. Typhimurium cells with a distinct biological function. (a) While expression of the exopolysaccharide cellulose provides a hydrophilic cell surface, expression of the amyloid curli fimbriae leads to a more hydrophobic surface as exemplified by assessment of surface tension [31]. A larger contact angle

inally Acetobacter [Gluconacetobacter] xylinum) to activate the biosynthesis of the exopolysaccharide cellulose [42]. Interactive with other nucleotide signaling systems and upon integration of still unknown signaling pathways, cyclic di-GMP acts as a nearly ubiquitous signal currency to exponentially translate and integrate a multitude of environmental and intracellular signals into the opposite sessility/motility lifestyle behavior concomitant with the cell cycle, cell morphology, metabolism, secondary metabolites, and physiology. The local and global elevation of the cyclic di-GMP signal thus results in the transition from a motile planktonic growth of single cells to an often sessile multicellular biofilm.
$\Theta$ indicates a more hydrophobic surface. Expression of the exopolysaccharide cellulose prevents adhesion (b), invasion (c), and secretion of the proinflammatory cytokine IL-8 (d) of $S$. Typhimurium to the gastrointestinal epithelial cell line HT-29, while expression of the amyloid curli fimbriae promotes adhesion, invasion, and secretion $[83,101,186]$. However, this microbial behavior is context dependent [41]. Rdar, red, dry, and rough.

The turnover of cyclic di-GMP is controlled by ubiquitous GGDEF and EAL or HD-GYP single or hybrid domain proteins encoded by numerous gene copies in variable numbers and ratios grossly correlated with genome size within a phylum $[4,43-45]$. Thereby, cyclic di-GMP is synthesized from two molecules of GTP by the diguanylate cyclase activity of GGDEF domains and hydrolyzed to linear $\mathrm{pGpG}$ or GMP through the phosphodiesterase activity of EAL or HD-GYP domains [46]. Both the $\mathrm{N}$-terminal signaling domains and the catalytic domains can receive regulatory signals which allosterically regulate the synthesis and hydrolysis of the messenger [47, 48]. For example, in the plant pathogen Agrobacterium tumefaciens, the level of cyclic di-GMP is controlled by a 
Fig. 3. Yin and Yang role of cyclic di-GMP signaling in stimulation of secretion of the pro-inflammatory cytokine IL- 8 by $S$. Typhimurium. Left: high intracellular cyclic di-GMP levels stimulate $\operatorname{csg} D$ expression and production of the extracellular matrix component cellulose. Cells in such a biofilm state do not stimulate production of the pro-inflammatory cytokine IL-8 [69, 83]. Middle: low intracellular cyclic diGMP levels stimulate secretion of monomeric flagellin by $S$. Typhimurium and IL-8 secretion by HT-29 cells is stimulated $[69,83]$. Right: cyclic di-GMP injected into cell lines and (upon the presence of receptors) extracellular cyclic di-GMP stimulates an innate immune response $[110,187$, 188]. Cyclic di-GMP, cyclic diguanylate monophosphate.

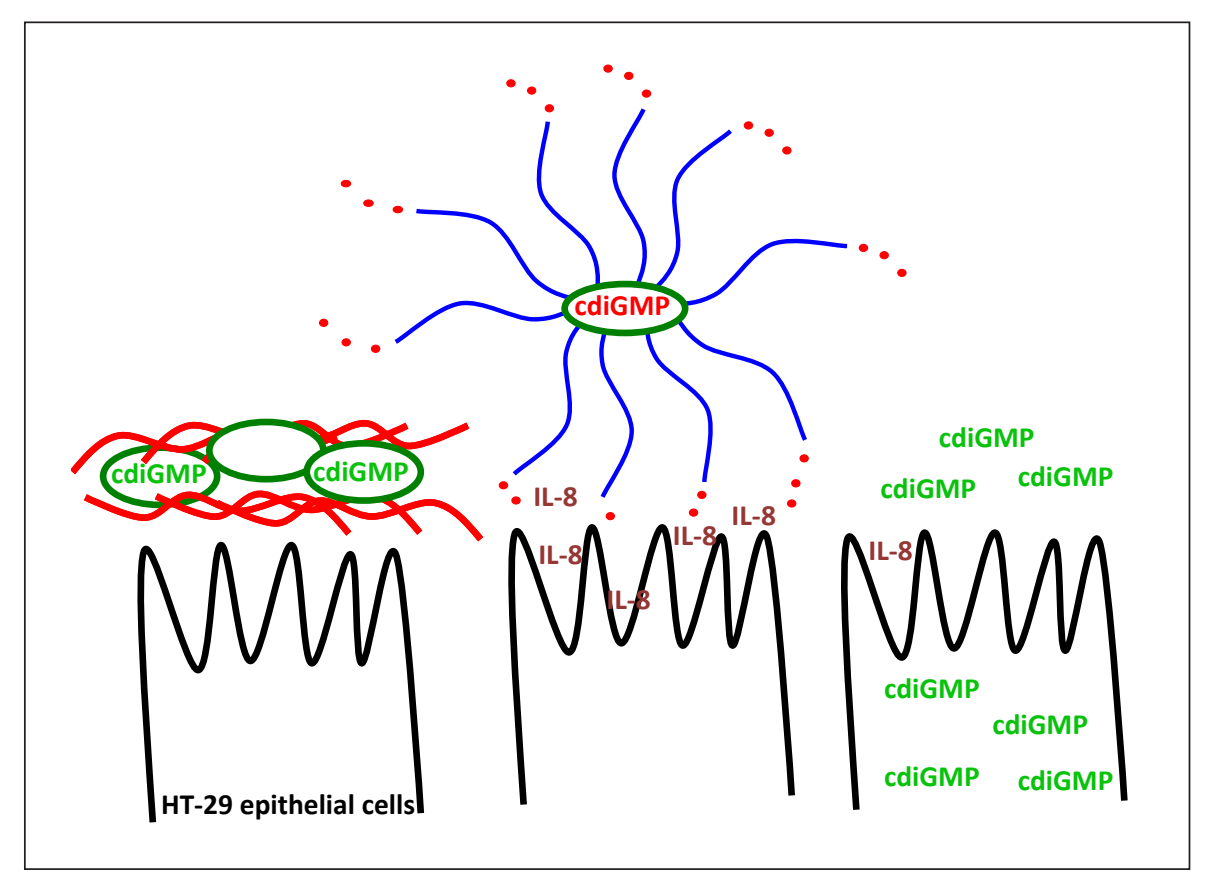

hybrid GGDEF-EAL protein, DcpA, that confers either diguanylate cyclase or phosphodiesterase activities depending on the absence or presence of the pteridine reductase PruA [49]. Similarly, in $P$. aeruginosa, the GGDEF-EAL protein MucR, confers diguanylate cyclase activity when the bacterium is planktonic while the EAL domain is active conferring a phosphodiesterase function when in a biofilm, with the activity growth responsive to nitric oxide [50]. In $S$. Typhimurium, the hybrid GGDEFEAL protein STM3388, the homolog of MucR, subsequently represses and activates production of the biofilm regulator CsgD during the growth phase [51].

In the signaling cascade downstream of synthesis, specific effector proteins directly or indirectly mediate the physiological output and phenotypes. Since the first cyclic di-GMP receptor was identified in 1987, namely the cellulose synthase of Gluconacetobacter xylinus [52, 53], with subsequent identification of C-terminal PilZ as the binding domain, numerous receptors with distinct cyclic di-GMP binding motifs including RNA aptamers have been elucidated [54-56].

Despite the wealth of experimental data that address various aspects of the cyclic di-GMP signaling system and its physiological consequences, one major question remains unanswered: how are biofilm extracellular matrix components differentially regulated to promote the various temporal and spatial restricted types of biofilms [57] and do these different types of biofilms display distinct

Virulence versus Biofilm of Salmonella

Typhimurium tolerance profiles? For example, the phosphodiesterase BinA of Vibrio fischeri adjacent of the Spy exopolysaccharide operon downregulates production of a cellulose-like exopolysaccharide [58]. In S. Typhimrurium, the evolved phosphodiesterase STM0551 within the type 1 fimbrial gene cluster represses the adjacent fimbrial genes [59].

\section{Regulation of Motility versus Sessility by Cyclic di-GMP Signaling}

Perhaps the most fundamental feature of cyclic diGMP is to confer the sessility versus motility lifestyle switch. First demonstrated with model signaling proteins including the diguanylate cyclase AdrA and the phosphodiesterase $\mathrm{YhjH}$, high cyclic di-GMP levels enhance biofilm formation [46, 60], while low cyclic di-GMP levels result in promotion of bacterial motility which can result in a planktonic lifestyle [60-62]. Cyclic di-GMP ubiquitously regulates sessility versus motility in all investigated bacteria with a multitude of physiological and metabolic adjustments, beyond the simple stimulation of biofilm transcription factors and biosynthesis enzymes that synthesize extracellular matrix components and post-translational downregulation of flagellar-based motility $[5,20$, 63]. Such a concomitant adjustment occurs, for example, in Vibrio cholerae where high level of cyclic di-GMP promotes DNA repair through the VpsT and VpsR cyclic di- 


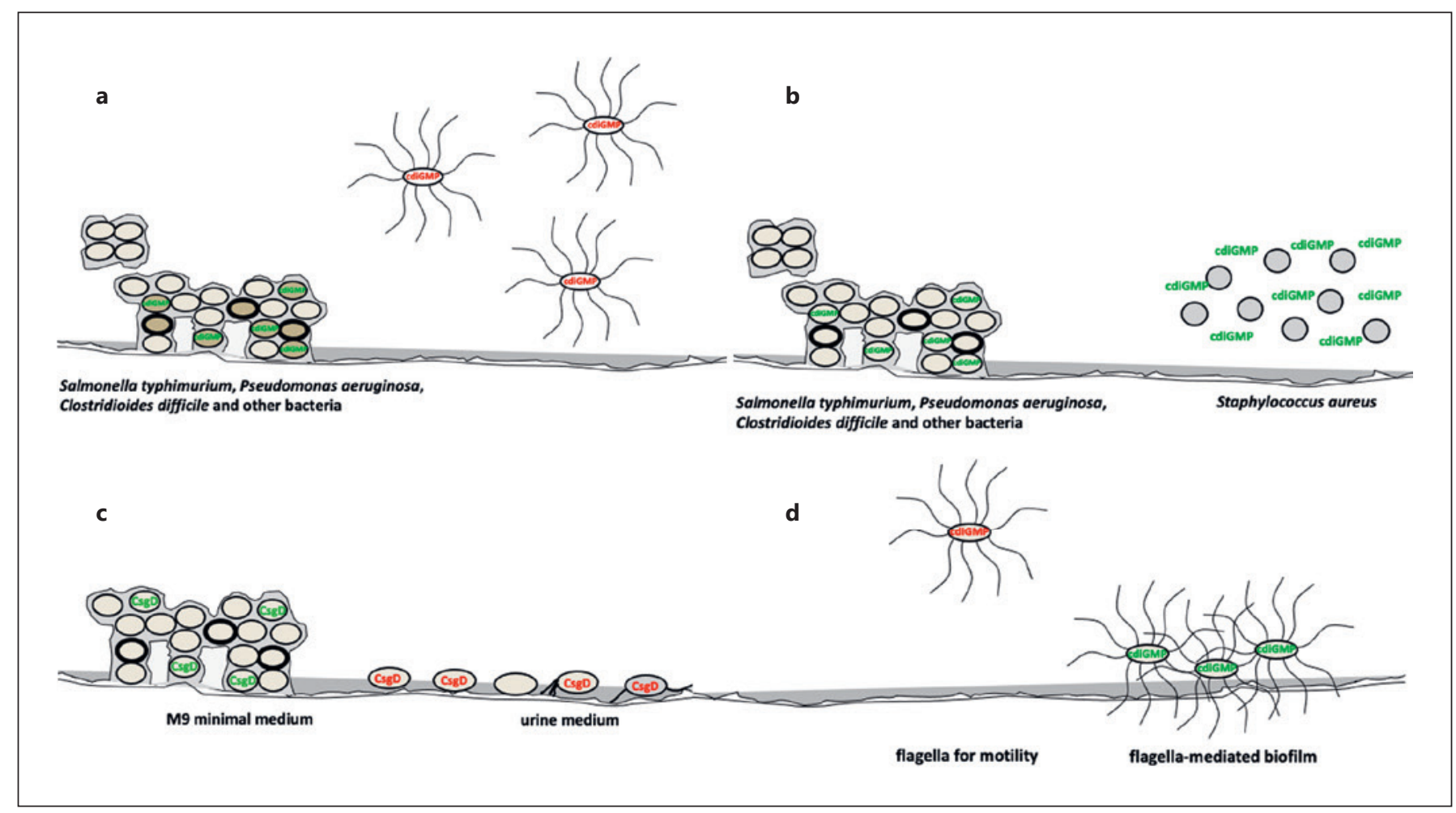

Fig. 4. Cyclic di-GMP and biofilm components in different context and its effect on biofilm formation by $S$. Typhimurium. (a) Sessility (biofilm formation) is stimulated by local or global high levels of cyclic di-GMP, while motility is stimulated by low levels of cyclic di-GMP in bacteria such as $S$. Typhimurium, $P$. aeruginosa, and Clostridioides difficile. (b) High intracellular cyclic di-GMP levels trigger biofilm formation of $S$. Typhimurium [46], while extracellularly applied cyclic di-GMP inhibits cell aggregation and biofilm formation by Staphylococcus aureus [73]. (c) Biofilm formation of $S$. Typhimurium is largely dependent on $\operatorname{csg} D$ in $\mathrm{M} 9$ minimal me-

GMP-dependent biofilm regulators. This regulation positively induces expression of the DNA repair gene 3-methyladenine glycosylase ( $\mathrm{tag}$ ) offering higher tolerance to DNA damaging conditions [64].

In $S$. Typhimurium and E. coli, the $c s g D$-mediated biofilm has been shown to be a major hub of cyclic di-GMP regulation with the orphan response regulator $\mathrm{CsgD}$ to promote the transcription of genes encoding biofilm matrix components. These include the $\operatorname{csg} B A C$ operon of minor and major curli fimbriae subunits and, indirectly, cellulose production by activating the gene for the diguanylate cyclase AdrA [66-68]. CsgD-mediated biofilms contribute not only to the transmission of $S$. Typhimurium, but also to biofilm formation and persistence in the context of the gastrointestinal tract, plants, and other environments (Fig. 3; [68-70]). The bistable expression of dium [40], while $\operatorname{csg} D$ expression inhibits biofilm formation in urine medium on a silicone surface (Wang and Römling, unpublished [78]). (d) Flagella promote swimming motility in liquid medium and swarming motility on a surface at low cyclic di-GMP levels, but also can be part of the extracellular biofilm matrix with, in $S$. Typhimurium, cell-associated flagellin to be upregulated upon expression of the diguanylate cyclase AdrA suggesting that production of flagella is increased [46, 83]. Cyclic di-GMP, cyclic diguanylate monophosphate.

CsgD ensures different subpopulations of cells with distinct biofilm formation and virulence properties [40,69], which provide the multicellular cell population with various immediate physiological possibilities.

With a cyclic di-GMP binding motif absent, $c s g D$ expression itself is a major target of cyclic di-GMP signaling on the transcriptional and post-transcriptional level (Fig. $1 ;[71,72])$. In contrast to the ubiquitous intracellular role of cyclic di-GMP, application of cyclic di-GMP extracellularly inhibits biofilm formation in bacteria such as Staphylococcus aureus (Fig. 4a; [73]). Indeed, extracellular cyclic di-GMP has been proposed as a treatment option against biofilm diseases; however, the effective mechanisms have been poorly explored.

$S$. Typhimurium and E. coli possess an array of fimbriae that can potentially promote biofilm formation 
[74-76] expressed under different, and often still undefined, environmental conditions with distinct regulatory schemes. Biofilm development of $S$. Typhimurium in batch cultures demonstrated a type 1 fimbriae and $\operatorname{csg} D$ mediated biofilm after $24 \mathrm{~h}$ that transforms into a solely csgD-mediated biofilm after $48 \mathrm{~h}$ [77]. Surprisingly, when grown on a silicone surface mimicking a urinary catheter in the artificial urine medium, $\operatorname{csg} D$ expression repressed biofilm formation as a $\operatorname{csg} D$ mutant showed higher biofilm formation as the wild type (Fig. 4b; Xiaoda Wang and Ute Römling, unpublished work; [78]). One explanation is possible repression of alternative biofilm matrix components such as type 1 fimbriae by $c s g D$. Another possibility is that adhesive components are surface-selective with deletion of $\operatorname{csg} D$ to expose silicone-specific adhesins on the cell surface. In this context, the composition of the biofilm of $P$. aeruginosa formed on the surface of the silicone catheter under urinary tract growth conditions has been shown to be fundamentally different from mediumgrown biofilms [79]. Motility is commonly negatively regulated by cyclic di-GMP in various bacteria $[46,80]$. A wide variety of motility modes are repressed by cyclic diGMP signaling including flagella-mediated swimming and swarming motility and type IV pili surface motility [81]. In S. Typhimurium, post-translational regulation by cyclic di-GMP, which binds to the PilZ domain protein $\mathrm{YcgR}$, leads to a conformational change in the protein $[80,82]$. Consequently, cyclic di-GMP loaded YcgR can form a complex with FliG and FliM proteins that are part of the flagella rotor. Although cyclic di-GMP can also inhibit expression of the flagellar regulon cascade in E. coli, overexpression of diguanylate cyclases in $S$. Typhimurium enhanced cell-associated flagellin most likely in the form of flagella [83]. This scenario is consistent with the idea that flagella have multiple roles as propellor of motility, as surface sensor and adherence factor, even constituting an extracellular matrix component of biofilms (Fig. 4c; $[84,85]$ ).

\section{Regulation of Acute versus Chronic Virulence by Cyclic di-GMP Signaling}

Cyclic di-GMP signaling regulates virulence of human, animal, and plant pathogens from $S$. Typhimurium and Mycobacterium tuberculosis, to the obligate intracellular pathogen Anaplasma phagocytophilum and the plant pathogen Xanthomonas campestris [5, 9, 26, 86, 87].

Being a major virulence factor in chronic and recurrent infections, acute infections also include temporal and spatial aspects of biofilm formation such as adherence, surface colonization and tolerance against immune components, antimicrobial agents, and detergents [88, 89]. Motility and chemotaxis are required for acute infection processes. Thus, cyclic di-GMP-mediated transition between acute and chronic infection properties is crucial for a successful infection $[62,90]$. Remarkable is the intrinsic inconsequence of high bacterial intracellular cyclic di-GMP concentration to lead to a biofilm status, which triggers a low-level immune response, while a low bacterial intracellular cyclic di-GMP level that leads to a virulence status provokes a high immune response. In contrast, host tissue available cyclic di-GMP provokes a substantial innate and adaptive immune response.

\section{Acute Virulence Phenotypes Regulated by Cyclic di-GMP Signaling}

Acute infections are based on short-term expansion of microbes that mostly involve planktonic (and motile) bacterial cells to employ the repertoire of virulence factors to invade and severely damage the tissue and to cause a substantial immune response. During acute infection by $S$. Typhimurium, the microorganisms are hypothesized to predominantly form biofilms in the gastrointestinal lumen with a fraction of cells breaching the epithelial cell lining. Nine cyclic di-GMP turnover proteins contribute to cecum colonization in the microbiota-depleted streptomycin-treated mouse model [91]. The contribution of (predicted) phosphodiesterases such as STM3615 (YhjK) and diguanylate cyclases such as STM2672 (YfiN) and Salmonella-specific STM4551 points to a complex role of cyclic di-GMP in persistent gut colonization (Fig. 1; [91]), with STM3615 also deficient in the colonization of mesenteric lymph nodes and the spleen (Lamprokostopoulou, Römling, and W.-D. Hardt, unpublished observations). Although the biofilm regulator $c s g D$ and curli are expressed in the gastrointestinal tract, the panel of regulatory cyclic di-GMP turnover proteins is distinct compared to regulation of plate-grown biofilms [51, 71, 92]. The putative phosphodiesterase STM3615, though, has an unconventional role in regulation of rdar biofilm formation in the background of deletion of $d s b A d s b B$ genes involved in periplasmic disulfide bond formation, with the involvement of the catalytic activity to be tested [93].

Although $S$. Typhimurium causes acute gastroenteritis, the disease is self-limiting in most immune-competent individuals due to the massive immune response combined with neutrophil influx. A particularly invasive $S$. Ty- 
phimurium clone, ST313, with enhanced virulence resembling typhoid fever and reduced biofilm formation, has emerged in Africa in HIV and malaria infected individuals and upon malnutrition [94]. The infection process of $S$. Typhimurium is regulated by cyclic di-GMP signaling and biofilm components at various stages as dissected by experimental studies with cell culture and animal models to show unique and distinct contributions of individual cyclic di-GMP turnover proteins (see below; [69, 83, 91, 95-97]).

Close association with epithelial cells is a characteristic of gastrointestinal pathogens and one of the first contacts of the bacteria with host tissue. S. Typhimurium forms biofilms on intestinal epithelial cells $[98,99]$. Surprisingly, the two $\operatorname{csg} D$-activated extracellular matrix components curli and cellulose have opposing roles in cell adherence. Curli fimbriae promote adhesion, while the exopolysaccharide cellulose inhibits adhesion of $S$. Typhimurium to the gastrointestinal cell line HT-29 (Fig. 2b; $[83,99,100]$ ). While a similar adherence pattern has been observed in a commensal and urinary tract infection E. coli strain [28, $101]$, the functionality of cellulose is context dependent; in the probiotic strain E. coli Nissle 1917, cellulose production promotes adhesion [41].

Invasion or uptake of $S$. Typhimurium into cells of the epithelial cell lining is one of the key steps in the pathogenicity of S. Typhimurium [102]. Saturation of the bacterial cell with cyclic di-GMP by overexpression of the diguanylate cyclase AdrA had a profound negative effect on invasion into the gastrointestinal epithelial cell line HT-29 [83]. Inhibition of virulence properties can be partially or even fully restored upon deletion of the biofilm regulator $\operatorname{csg} D$, identifying $\operatorname{csg} D$ as one central hub for the acute virulence versus biofilm switch at the epithelial cell lining in S. Typhimurium [83]. Relieve of invasion occurs further through inhibition of the production of cellulose and capsule extracellular matrix components (Fig. 2c; $[31,65,83])$. Cellulose production can be activated, though, by cyclic di-GMP independently of CsgD [31, 103]. Possible mechanisms of reduction of invasion are prevention to establish adherence and shielding the type III secretion system-1 nanomachine via production of the cellulose exopolysaccharide [83, 104].

Dissecting the effect of individual cyclic di-GMP turnover proteins showed that 10 out of 20 deletions of individual GGDEF/EAL domain genes altered the invasion phenotype with 7 mutants showing a conventional and three mutants showing an unconventional phenotype. The molecular basis of interference with invasion has started to become unraveled for some of these GGDEF/ EAL domain proteins (see below).
Breaching the epithelial cell lining by $S$. Typhimurium causes massive secretion of the pro-inflammatory cytokine IL-8, which subsequently attracts neutrophils to clear the infection [105]. Again, flooding the bacterial cell with cyclic di-GMP abolishes induction of the pro-inflammatory cytokine IL- 8 in the epithelial cell line HT-29 (Fig. 2d, 3; [83]). Deletion of the genes for 6 cyclic diGMP turnover proteins affects IL- 8 secretion, while three of those proteins affect both invasion and IL-8 secretion. In contrast, secreted cyclic di-GMP and cyclic di-GMP systemically applied to the host is commonly immunostimmulatory, with cyclic di-GMP recognized as a noncytotoxic adjuvant $[17,83,106-110]$.

Macrophages take up Salmonella beyond the gastrointestinal epithelial barrier for transport to inner organs via the blood stream [111-113]. S. Typhimurium uptake and survival in macrophages has been investigated in Salmonella susceptible animal models by mimicking Salmonella enterica serovar Typhi infection in humans long before the invasive S. Typhimurium ST313 clone emerged [69, 114]. S. Typhimurium produces cellulose within the Salmonella-containing vacuole in macrophages, which restricts its proliferation and attenuates acute virulence during systemic infection of Salmonella susceptible mice (Fig. 5a; $[39,96])$. Different mechanisms can lead to alteration of cellulose production such as the MtgC virulence factor which interacts with the $\mathrm{F}_{1} \mathrm{~F}_{0}$ ATP synthase to restrict cellulose biosynthesis. The cellulase BcsZ, which substantially upregulates virulence of $S$. Typhimurium, suggests that dysregulated biosynthesis of cellulose and not expression of the cellulose synthase BcsA is a determinative virulence modifying factor. Of note, ST313 clone members of $S$. Typhimurium possess a number of single nucleotide polymorphisms inside open reading frames and in intergenic regions, which have been shown to modulate virulence of this organism. For example, an amino acid substitution in the sensory Cache 1 domain of the diguanylate cyclase STM1987 causes reduced cellulose production but enhanced murine and human macrophage survival [97]. Equally, ST313 representatives harbor mutations in the gene for the alkaline phosphatase superfamily member BcsG [115]. As BcsG stabilizes the cellulose synthase BcsA post-translationally in combination with covalent modifications of the glucose subunits growing glucan chain by the phosphoethanolamine phospholipid headgroup [27, 29], the reduced cellulose biosynthesis is predicted to lead to enhanced proliferation in macrophages. Thus, intracellular proliferation without cellulose production opposes growth restriction upon biosynthesis of the cellulose biofilm matrix 


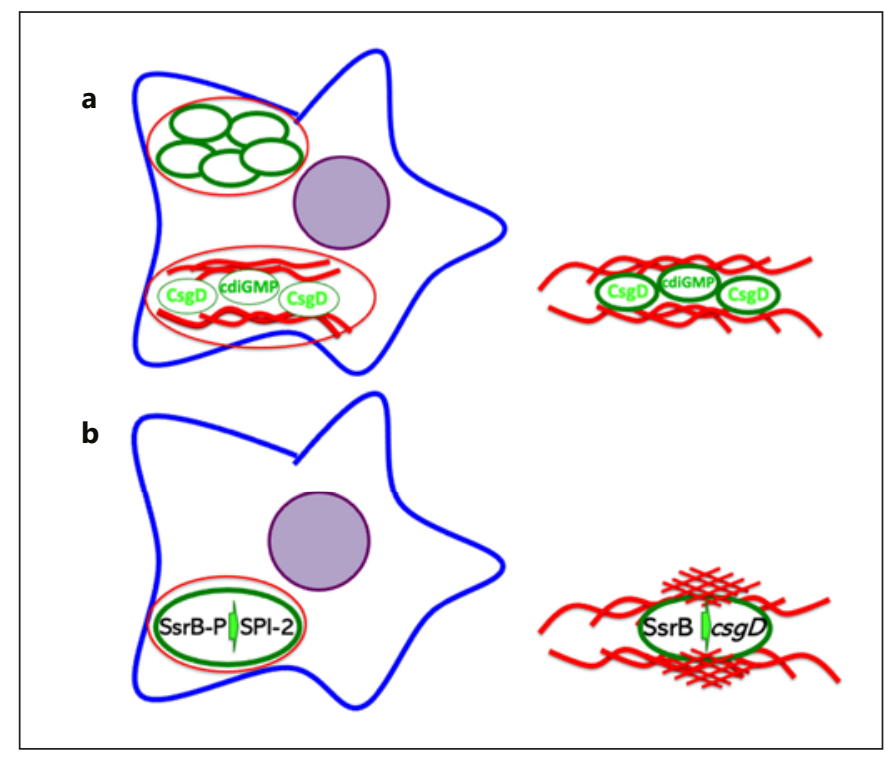

Fig. 5. Contribution of biofilm components and virulence factors to virulence and biofilm formation in S. Typhimurium. (a) Cellulose production and $c s g D$ expression of $S$. Typhimurium establish extracellular and intracellular biofilms [5, 39. 40, 91, 95, 96]. Left: $S$. Typhimurium produces cellulose inside macrophages. Right: $S$. Typhimurium produces cellulose in extracellular biofilms. (b) The phosphorylated SsrB response regulator of the SsrA/SsrB 2-component system stimulates expression of the TTSS-2 2-component system inside the Salmonella-containing vacuole of macrophages [131], while the unphosphorylated SsrB response regulator aids promoter activation of the $\operatorname{csg} D E F G$ operon encoding $\operatorname{csg} D$, the rdar biofilm activator, and additional genes required for the biogenesis of amyloid curli fimbriae [120,132]. Cyclic di-GMP, cyclic diguanylate monophosphate.

component, which basically oppositely reflects biofilm formation versus planktonic cell proliferation in the extracellular gastrointestinal space. Whether and, if so, why cellulose-producing bacteria are more susceptible to intracellular antimicrobial defense mechanisms needs to be shown. The channeling of glucose into cellulose instead of glycolysis which is required for $S$. Typhimurium in macrophages might restrict proliferation [116].

In bone-marrow-derived macrophages, at least three different subpopulations of intracellular Salmonella: fast, moderate, and slow growing have been identified [95]. Counterintuitively, the cellulose-producing slow-growing subpopulation was significantly more depleted upon deletion of three cyclic di-GMP-specific phosphodiesterases required to lower cyclic di-GMP levels shortly after entry into the macrophages (Fig. 1). The requirement for survival upon immune cell exposure might contribute that STM3615, encoding one of two redox-responsive

Virulence versus Biofilm of Salmonella

Typhimurium phosphodiesterases, required for proliferation in macrophages, is also required for luminal colonization [91].

Intracellular and extracellular cellulose production provides an excellent example of the distinct roles of biofilms within host cells versus the luminar space. Within host cells, proliferation of planktonic cells is promoted, while slow-growing cells in a cellulose-producing biofilm status might persist without destruction of the host cell on a longer time scale. Outside host cells in the extracellular gastrointestinal space, the large number of biofilm cells outnumbers the few planktonic cells that breach the epithelial cell lining. Whether other biofilm types are expressed in immune cells cannot be excluded.

\section{Contribution of Type III Secretion System-1}

Cyclic di-GMP contributes at many stages to adjust virulence properties of $S$. Typhimurium; however, which of these processes are affected on the molecular level remains unknown. S. Typhimurium possesses two type III secretion systems (TTSS- 1 and TTSS-2) needle-like nanomachines that tip adhere to the epithelial cell to inject effector proteins for host cell manipulation. Invasion of $S$. Typhimurium into epithelial cells requires genes of the Salmonella pathogenicity island 1 that code for the TTSS1 [117]. TTSS- 1 is regulated by a variety of extra- and intracellular signals [118-120] such as small intestine growth conditions with low oxygen and high salt to promote optimal expression of TTSS- 1 proteins. Regulatory pathways for TTSS-1 expression converge at the transcriptional regulator HilA [117]. Polysaccharide components on the surface of bacteria have been demonstrated to interfere with invasion and/or type III secretion system functionality. The length of the O-antigen chain of lipopolysaccharide [121-123] and likewise in S. Typhi, the Vi-capsule [124] counteracts invasion of host cells. Inhibition by extracellular matrix components is, however, not universal as in P. aeruginosa biosynthesis of extracellular biofilm matrix does not seem to correlate with interference with type III secretion functionality [90]. On the other hand, in $S$. Typhimurium, adhesive curli fimbriae mediate adherence $[28,83]$, a prerequisite for TTSS-1 functionality and invasion [125].

In many bacteria including $S$. Typhimurium, TTSS$1 / 2$ systems are subject to regulation by cyclic di-GMP signaling on the transcriptional and post-transcriptional level [119]. Thereby, biofilm formation and virulence properties can be closely linked as expression of type III secretion system components can be upregulated in bio- 
films $[93,126]$ and required for the formation of mature biofilms and multicellular behavior [127, 128].

In $S$. Typhimurium, $c s g D$ and cyclic di-GMP signaling interfere with TTSS- 1 functionality downstream of the activity of the TTSS- 1 central regulator HilA $[6,83,91]$. Thereby, cyclic di-GMP-mediated $c s g D$ expression has been exemplarily shown to inhibit the secretion of the TTSS- 1 effector SopE2 [83, 91, 128, 129]. In csgD competent cell, cyclic di-GMP turnover proteins, diguanylate cyclases, and phosphodiesterases regulate secretion of effector proteins by their scaffold rather than by catalytic activity [71]. Those findings are consistent with results from $P$. aeruginosa where TTSS-mediated cytotoxicity toward the $\mathrm{CHO}$ cell line is affected by cyclic di-GMP signaling [90]. The subset of GGDEF/EAL mutants demonstrating alteration in cytotoxicity toward the $\mathrm{CHO}$ cell line was only partially overlapping with the subset contributing to virulence in a burn wound mouse model.

\section{Contribution of Type III Secretion System-2}

The TTSS-2 is required for survival and proliferation of $S$. Typhimurium inside the Salmonella-containing vacuole [130]. The SsrA-SsrB 2-component system is regulated by the transcriptional regulator HilD, which affects the expression of HilA coordinating the expression of TTSS- 1 and TTSS-2. A major transcriptional regulator of the TTSS- 2 is the response regulator $\mathrm{SsrB}$ phosphorylated by its cognate histidine kinase SsrA [131]. On the other hand, though, in the lumen of the gastrointestinal tract of the nematode Caenorhabditis elegans unphosphorylated SsrB is an anti-virulence factor to be required for the activation of transcription of the biofilm regulator $\operatorname{csg} D$ (Fig. 5b; [132]). The association of biofilm formation with TTSS-2 is more tight than previously thought as the TTSS-2-encoded MerR-like transcriptional regulator MlrB repressess $\operatorname{csg} D$ expression inside macrophages [133]. These findings showed that biofilm formation is tightly counterregulated with virulence in $S$. Typhimurium by even using the same components. Of note, not only SsrB but also CsgD directs biofilm formation in its unphosphorylated form [72].

\section{Regulation of the IL-8 Response by Cyclic di-GMP Signaling}

In the absence of cellulose production, $S$. Typhimurium can effectively bind to and invade epithelial cells via curli fimbriae and subsequently trigger production of the pro-inflammatory cytokine via curli-bound flagellin (Fig. 2d; [37, 56, 101]). High levels of cyclic di-GMP, though, did not trigger IL- 8 production by HT-29 cells [83]. Stimulation of secretion of the pro-inflammatory cytokine IL-8 is recovered upon deletion of $\operatorname{csg} D$, which relieves the secretion of monomeric flagellin. The nonstimulatory phenotype of $S$. Typhimurium during high cyclic di-GMP concentrations may possibly be a result of inhibition of the secretion of monomeric flagellin inducing IL-8 in the HT-29 cell line [134].

Similar to invasion, the cyclic di-GMP signaling system regulates flagellin secretion, as monitored by stimulation of the secretion of the pro-inflammatory cytokine IL-8, by a complex network of cyclic di-GMP turnover proteins (Fig. 1, 3; [91]). While the diguanylate cyclase STM1287 conventionally represses IL-8 secretion, the two EAL domain proteins, STM0468 and STM4264, and the GGDEF-EAL proteins, STM1703 and STM2503, stimulate IL-8 secretion equally as the degenerated GGDEF-EAL protein STM3375. Several of the EAL proteins seem to work in the same pathway as double mutants do not additively diminish the phenotype.

\section{Flagella Regulon-Related Phenotypes Affected by Cyclic di-GMP Signaling}

With the flagellar regulon cascade delicately manipulated on different levels, the flagellum is not only a bacterial virulence factor with swimming and swarming motility to promote colonization and tissue invasion $[83,136]$. Monomeric flagellin is recognized as a major pathogenassociated molecular pattern (PAMP) and systemic antigen being a major antigen in Crohn's disease $[136,137]$.

Differential in vivo affinities for cyclic di-GMP for the flagellar motor break, the cyclic di-GMP receptor YcgR $(2 \mu \mathrm{M})$, and subsequently the cellulose synthase BcsA (8 $\mu \mathrm{M}$ ) involved in the inhibition of bacterial motility and in increase in cellulose-based biofilm matrix production, respectively, ensure coordinated steps toward $S$. Typhimurium biofilm formation $[135,138]$. During bacterial infection, the polymeric flagellar filament can act as a virulence factor with secreted monomeric flagellin as an immunogen triggering innate as well as adaptive host response.

Recognition of flagellin monomers by epithelial cells occurs by pattern recognition receptors. Toll-like receptors (TLRs) are a group of important transmembrane pattern recognition receptors and until now, 15 TLRs have been identified, from which TLR 1-10 are found in humans [139]. TLRs have been found to reside 
on the surface or within cell compartments of not only epithelial and innate immune cells, but also neuronal cells, endothelial cells, and other cell types. After recognition of PAMPs, TLRs trigger a signaling cascade, which leads to the release of pro-inflammatory cytokines in order to subsequently promote an immune response. Recognition of flagellin by TLR 5 and in the case of plants by FLS2 [140] subsequently leads to NF-kB activation, chemokine release, $\mathrm{T}$-cell activation, and other inflammatory phenotypes with flagella production to be shut off at the later stage of infection [141, 142]. In bacterial infection of plants, high intracellular cyclic di-GMP concentrations drastically reduce the virulence of Pseudomonas syringae pv. tomato (Pto) DC3000 through inhibition of flagellar motility among other pleiotropic effects resulting from cyclic di-GMP signaling on bacterial behavior [143, 144]. Stimulation of the secretion of monomeric flagellin has been observed in response to host cells [82], and it remains to be shown whether this stimulation involves a cyclic diGMP signaling pathway. Equally whether, and how, secretion of monomeric flagellin is coupled to the flagella biosynthesis process is unknown [128]. In conclusion, the above described work shows that secretion of monomeric flagellin is dependent on the expression of biofilm regulators and cyclic di-GMP signaling [83, 91].

The two evolved EAL domain only proteins STM1344 and STM1697 do not possess phosphodiesterase activity nor do these proteins bind cyclic di-GMP but inhibit the flagella regulon by inhibiting the activity of the class 1 regulator $\mathrm{FlhD}_{2} \mathrm{C}_{4}$ through protein-protein interactions [145-147]. In this way, STM1344 and STM1697, both contribute to regulation of swimming motility and phase variation of flagellar expression $[145,146]$. Both proteins promote virulence presumably by their contribution to the delicate regulation of expression of flagellar antigenic filaments. Furthermore, STM1344 promotes resistance to Salmonella-induced oxidative stress and inhibits rapid macrophage killing [148].

On the other hand, the EAL-only protein $\mathrm{YhjH}$ is the only motility-dedicated phosphodiesterase [92, 135]. $\mathrm{YhjH}$, despite possessing catalytic activity, is actually more closely related to STM1344 and STM1697 than to any other EAL domain in S. Typhimurium [67, 149]. Three diguanylate cyclases differentially feed into the inhibition of motility addressing the YcgR motor break (STM2672), the BcsA cellulose synthase (STM1987), or both receptors (STM4551) [135].

Virulence versus Biofilm of Salmonella

Typhimurium

\section{Bacterial Cyclic di-GMP Signaling in Immunity}

Overgrowth of the microbial flora is prevented by an outer and inner mucus layer on the surface of the epithelium [150], which provides a mechanical, physicochemical, and biological barrier accumulating bacteriolytic enzymes like lysozyme and antimicrobial peptides secreted from $\mathrm{Pa}$ neth cells $[151,152]$. In addition, nutritional immunity challenges, for example, iron acquisition by microbial produced siderophores [153, 154]. Microbial secreted cyclic diGMP can contribute not only to stimulate innate immunity, but to overcome nutritional immunity $[12,109]$. Upon ingestion, few $S$. Typhimurium cells penetrate the mucus layer to reach the mucosal cell lining as the first barrier [155]. In mammalian as well as in plant host cells, innate immune receptors located in the cell membrane and intracellular receptors recognize PAMPs and induce an innate immune response known as pattern-triggered immunity (PTI) as a first line of response $[156,157]$. Commensal bacteria trigger low-level PTI, evade, or even suppress PTI in order to successfully colonize the host [158]. PathogenPAMPs include the following: lipid A part of the lipopolysaccharide present in the outer membrane of Gram-negative bacteria, components of the bacterial cell wall such as peptidoglycan, microbial DNA, and physiological amyloids such as curli [159]. Another PAMP that plays an important role in triggering mucosal innate immune responses, as described above, is flagellin [160].

Based on initial reports [106, 161], cyclic di-GMP was recognized as a PAMP, to trigger protective host innate and adaptive immune responses [110]. The comprehensive stimulation of immunity might contribute cyclic di-GMP to be delivered exogenously in a murine model of bacterial pneumonia. A local or systemic administration of cyclic diGMP prior to challenge with Klebsiella pneumoniae resulted in significantly increased animal survival and bacterial reduction in the lung and blood [110]. In combination with the initiation of robust innate and adaptive immune responses characterized by enhanced accumulation of neutrophils and alphabeta T cells, as well as activated natural killer cells and macrophages expressing inducible nitric oxide synthase and nitric oxide, the cell recruitment was associated with early elevated expression of chemokines and type I cytokines. These initial fundamental findings established cyclic di-GMP and subsequently analogous cyclic dinucleotides not only as effective immune-modulators and enhancers, but also as potential anti-biofilm and anticancer agents. The subsequent identification of cyclic di-GMP and other cyclic di-nucleotide receptors in mammals paved the way for the identification of the central cGAS-cGAMP-

J Innate Immun 2022;14:275-292 285 


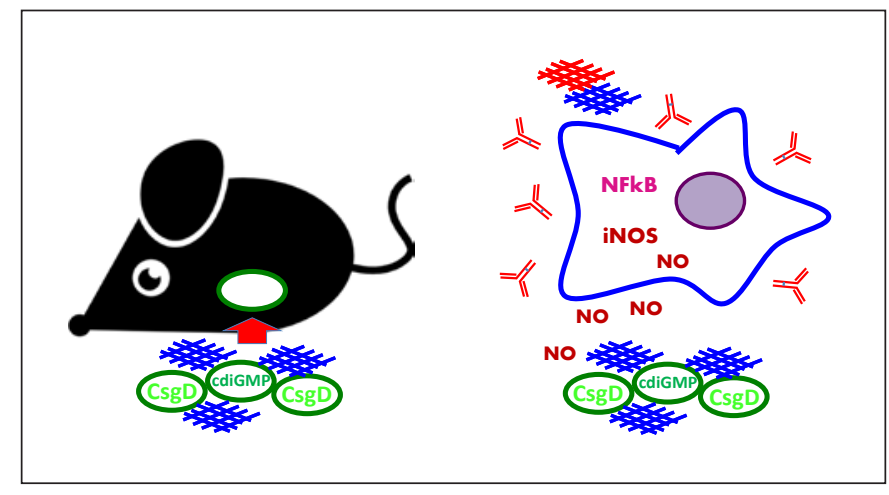

Fig. 6. Contribution of the biofilm component curli to intestinal barrier function and invasion versus autoimmunity, seed function, and inflammation. Luminally expressed curli are recognized by TLR2/ TLR1 in combination with CD14. This receptor recognition of amyloid fibers induces a phosphatidylinositol 3-kinase-dependent pathway to strengthen the epithelial barrier function in order to prevent invasion of cells into deeper tissue (left). Amyloid fibers or bacterial cells expressing curli located systemically or exposed to immune cells cause the production of autoimmune antibodies, enhance amyloid formation, and cause an inflammatory response via iNOS, NFkap$\mathrm{paB}$, and other pathways. Mouse figure is taken from https://www. flaticon.com/free-icon/mouse-black-animal_40508. TLR, toll-like receptor; cyclic di-GMP, cyclic diguanylate monophosphate.

STING axis for sensing and responding to cytoplasmic nucleic acids [162-164]. Cyclic di-GMP can also activate the intracellular sensor STING, suggesting that cytosolic bacteria release this immune activator [38, 165]. Upon Salmonella infection and subsequent cyclic di-GMP release, STING activation induces Interferon Regulatory Factor 1 responsible for TH17 subspecification in the mucosal immune system [166]. The association between high cyclic diGMP concentration in the colon and stabilization of STING by cyclic di-GMP-induced ubiquitination in a mouse model of spontaneous colitis indicates an underestimated degree of interkingdom cross talk by this ubiquitous second messenger [167]. These observations in an animal model also put forward that substantial secretion of cyclic di-GMP and other cyclic di-nucleotides can occur, perhaps not only by gastrointestinal bacteria such as E. coli, but also lung pathogens like M. tuberculosis [168, 169].

\section{The Yin and Yang of Biofilm Formation in the Gastrointestinal Tract}

The biofilm regulator $\operatorname{csg} D$ is expressed in the gastrointestinal tract and can be required for colonization (Fig. 6; [170, 171]). Consequently, curli (and other physi- ological microbial amyloids) are produced during acute and chronic infections [172-175]. These amyloid PAMPs are recognized by TLR1/TLR2 in combination with the CD14 adaptor [176-178] and intracellular NOD-like receptors [179]. Thereby, recognition of curli by host immune components leads, on the one hand, to the strengthening of the epithelial barrier function and dampens inflammation in the gut $[180,181]$ and, on the other hand, upon breaching of the intestinal barrier, to autoantibody formation with delayed onset of autoimmunity, inflammation, and functioning as a seed to promote enhanced aggregation leading to neurogenerative diseases [173, 182-185]. The $\operatorname{csg} D$ biofilm activator is impaired or absent in the invasive $S$. Typhimurium clone ST313, equally as in S. Typhimurium [94]. The deficiency to produce curli may contribute to enhanced translocation as demonstrated for non-ST313 curli mutants [181]. Thus, in the luminar space, production of these physiological amyloids prevents their own, other amyloids and bacterial cell translocation to protect the host from systemic disease and overshooting inflammatory processes.

\section{Conclusion}

Although biofilms are commonly considered as one physiological state in a bacterium, various modes of biofilm formation exist that might have different consequences on microbial host interactions. Thereby, even concomitantly expressed extracellular matrix components can play opposite roles in microbial physiology. The major regulator of biofilm formation, the ubiquitous second messenger cyclic di-GMP, delicately regulates biofilm formation and pathogen-host interactions. Thereby, extracellularly of bacteria, the role of cyclic diGMP and other cyclic di-nucleotides in a host environment is in stark contrast to the intracellular role of cyclic di-GMP in bacteria. Cyclic di-GMP is an intracellular second messenger signaling molecule in bacteria that promotes biofilm formation, which transforms cells into a low virulence, (relatively) low immunogenic status that is more similar to persistent commensalism than reflecting an acutely virulent pathogen. However, microbial secreted or systemically and mucosally applied cyclic diGMP, cyclic di-AMP, and other cyclic di-nucleotides either stimulate or also inhibit immune responses. In this way, bacteria have the possibility to distinctively manipulate the immune system response. To what extent this secretion process occurs in bacteria, whether and how it is regulated, and in the case of secretion of cyclic di-nucle- 
otides by E. coli and M. tuberculosis, its precise molecular mechanisms need to be unraveled. Furthermore, the interaction of biofilms with immune cells such as $\mathrm{M}$ cells and dendritic cells at the interface between innate and adaptive immune response with cyclic di-nucleotide-producing bacteria has not been thoroughly explored.

\section{Acknowledgments}

Infection experiments with S. Typhimurium in the streptomycin-treated animal model were performed in collaboration with Wolf-Dieter Hardt at ETH Zürich, Switzerland. The authors appreciate the contribution of all previous and present colleagues to this research.

\section{Conflict of Interest Statement}

The authors have no conflicts of interest to declare.

\section{Funding Sources}

Work by the authors described in this review has been supported by the Swedish Research Council, Scientific Council for Natural Sciences and Engineering, the Marie Curie Innovative Training Network "EUs IMO-Train," and the Karolinska Institutet.

\section{Author Contributions}

Agaristi Lamprokostopoulou and Ute Römling drafted the review.

\section{References}

1 Kroupitski Y, Gollop R, Belausov E, Pinto R, Sela Saldinger S. Salmonella enterica growth conditions influence lettuce leaf internalization. Front Microbiol. 2019;10:639.

2 Hamilton S, Bongaerts RJ, Mulholland F, Cochrane B, Porter J, Lucchini S, et al. The transcriptional programme of Salmonella enterica serovar Typhimurium reveals a key role for tryptophan metabolism in biofilms. BMC Genomics. 2009 Dec 11 [cited 2021 May 12]; 10(1):599.

3 D’Argenio DA, Miller SI. Cyclic di-GMP as a bacterial second messenger. Microbiology. 2004 Aug;150(Pt 8):2497-502.

4 Römling U, Galperin MY, Gomelsky M. Cyclic di-GMP: the first 25 years of a universal bacterial second messenger. Microbiol Mol Biol Rev. 2013 Mar;77(1):1-52.

5 Römling U, Jonas K, Melefors Ö, Grantcharova N, Lamprokostopoulou A. Hierarchical control of rdar morphotype development of Salmonella enterica by cyclic di-GMP. In: The second messenger cyclic di-GMP [Internet]. American Society of Microbiology; 2010. p. 137-55. Available from: https://www. a s m s c i e n c e. org/content/ book/10.1128/9781555816667.ch10.

6 Römling U. Cyclic di-GMP signaling in Salmonella enterica serovar Typhimurium. In: Chou S-H, Guiliani N, Lee VT, Römling U, editors. Microbial cyclic di-nucleotide signaling [Internet]. Cham: Springer International Publishing; 2020. p. 395-425.

7 Corrigan RM, Gründling A. Cyclic di-AMP: another second messenger enters the fray. Nat Rev Microbiol. 2013 Aug;11(8):513-24.

8 Davies BW, Bogard RW, Young TS, Mekalanos JJ. Coordinated regulation of accessory genetic elements produces cyclic di-nucleotides for V. cholerae virulence. Cell. 2012 Apr; 149(2):358-70.

Virulence versus Biofilm of Salmonella

Typhimurium
9 Aravind L, Anantharaman V, Iyer LM. Evolutionary connections between bacterial and eukaryotic signaling systems: a genomic perspective. Curr Opin Microbiol. 2003;6(5):490.

10 Blommers MJ, Haasnoot CA, Walters JA, van der Marel GA, van Boom JH, Hilbers CW. Solution structure of the 3'-5' cyclic dinucleotide $\mathrm{d}(\mathrm{pApA})$. A combined NMR, UV melting, and molecular mechanics study. Biochemistry. 1988 Nov;27(22):8361-9.

11 Burroughs AM, Zhang D, Schäffer DE, Iyer LM, Aravind L. Comparative genomic analyses reveal a vast, novel network of nucleotidecentric systems in biological conflicts, immunity and signaling. Nucleic Acids Res. 2015 Dec;43(22):10633-54.

12 Gao YG, Robinson H, Guan Y, Liaw YC, van Boom JH, van der Marel GA, et al. Molecular structure of two crystal forms of cyclic triadenylic acid at $1 \mathrm{~A}$ resolution. J Biomol Struct Dyn. 1998 Aug;16(1):69-76.

13 Whiteley AT, Eaglesham JB, de Oliveira Mann CC, Morehouse BR, Lowey B, Nieminen EA, et al. Bacterial cGAS-like enzymes synthesize diverse nucleotide signals. Nature. 2019 Mar 14 [cited 2021 May 6];567(7747): 194-9. Available from:

14 Kazlauskiene M, Kostiuk G, Venclovas Č, Tamulaitis G, Siksnys V. A cyclic oligonucleotide signaling pathway in type III CRISPRCas systems. Science. 2017 Aug;357(6351): 605-9.

15 Lau RK, Ye Q, Birkholz EA, Berg KR, Patel L, Mathews IT, et al. Structure and mechanism of a cyclic trinucleotide-activated bacterial endonuclease mediating bacteriophage immunity. Mol Cell. 2020 Feb;77(4):723-33.e6.

16 Niewoehner O, Garcia-Doval C, Rostøl JT, Berk C, Schwede F, Bigler L, et al. Type III CRISPR-Cas systems produce cyclic oligoadenylate second messengers. Nature. 2017 Aug;548(7669):543-8.
17 Morehouse BR, Govande AA, Millman A, Keszei AFA, Lowey B, Ofir G, et al. STING cyclic dinucleotide sensing originated in bacteria. Nature. 2020 Oct;586(7829):429-33.

18 Christen M, Kulasekara HD, Christen B, Kulasekara BR, Hoffman LR, Miller SI. Asymmetrical distribution of the second messenger c-di-GMP upon bacterial cell division. Science. 2010 Jun;328(5983):1295-7.

19 Martín-Rodríguez AJ, Reyes-Darias JA, Martín-Mora D, González JM, Krell T, Römling U. Reduction of alternative electron acceptors drives biofilm formation in Shewanella algae. NPJ Biofilms Microbiomes. 2021 Jan;7(1):9.

20 Fernandez NL, Hsueh BY, Nhu NTQ, Franklin JL, Dufour YS, Waters CM. Vibrio cholerae adapts to sessile and motile lifestyles by cyclic di-GMP regulation of cell shape. Proc Natl Acad Sci U S A. 2020 Nov;117(46):29046-54.

21 He M, Ouyang Z, Troxell B, Xu H, Moh A, Piesman J, et al. Cyclic di-GMP is essential for the survival of the lyme disease spirochete in ticks. PLoS Pathog. 2011 Jun;7(6):e1002133.

22 Joshi A, Mahmoud SA, Kim SK, Ogdahl JL, Lee VT, Chien P, et al. c-di-GMP inhibits LonA-dependent proteolysis of TfoY in Vibrio cholerae. PLoS Genet. 2020 Jun; 16(6): e1008897.

23 Osbourne DO, Soo VW, Konieczny I, Wood TK. Polyphosphate, cyclic AMP, guanosine tetraphosphate, and c-di-GMP reduce in vitro Lon activity. Bioengineered. 2014;5(4):264-8.

24 Römling U. Cyclic di-GMP, an established secondary messenger still speeding up. Environ Microbiol. 2012 Aug;14(8):1817-29.

25 Cole SJ, Lee VT. Cyclic Di-GMP signaling contributes to Pseudomonas aeruginosa-mediated catheter-associated urinary tract infection. J Bacteriol. 2016 Jan;198(1):91-7. 
26 Lai TH, Kumagai Y, Hyodo M, Hayakawa Y, Rikihisa Y. The Anaplasma phagocytophilum $\mathrm{PleC}$ histidine kinase and $\mathrm{PleD}$ diguanylate cyclase two-component system and role of cyclic Di-GMP in host cell infection. J Bacteriol. 2009 Feb;191(3):693-700.

27 Sun L, Vella P, Schnell R, Polyakova A, Bourenkov G, Li F, et al. Structural and functional characterization of the BcsG subunit of the cellulose synthase in Salmonella Typhimurium. J Mol Biol. 2018 Sep;430(18 Pt B):317089.

28 Wang X, Rochon M, Lamprokostopoulou A, Lünsdorf H, Nimtz M, Römling U. Impact of biofilm matrix components on interaction of commensal Escherichia coli with the gastrointestinal cell line HT-29. Cell Mol Life Sci. 2006 Oct;63(19-20):2352-63.

29 Thongsomboon W, Serra DO, Possling A, Hadjineophytou C, Hengge R, Cegelski L. Phosphoethanolamine cellulose: a naturally produced chemically modified cellulose. Science. 2018 Jan;359(6373):334-8.

30 Römling U, Sierralta WD, Eriksson K, Normark S. Multicellular and aggregative behaviour of Salmonella Typhimurium strains is controlled by mutations in the agfD promoter. Mol Microbiol. 1998 Apr;28(2):249-64.

31 Zogaj X, Nimtz M, Rohde M, Bokranz W, Römling U. The multicellular morphotypes of Salmonella Typhimurium and Escherichia coli produce cellulose as the second component of the extracellular matrix. Mol Microbiol. 2001 Mar;39(6):1452-63.

32 Zogaj X, Bokranz W, Nimtz M, Römling U. Production of cellulose and curli fimbriae by members of the family Enterobacteriaceae isolated from the human gastrointestinal tract. Infect Immun. 2003 Jul 1;71(7):4151-8.

33 Biesecker SG, Nicastro LK, Wilson RP, Tükel Ç. The functional amyloid curli protects Escherichia coli against complement-mediated bactericidal activity. Biomolecules. 2018 Jan; $8(1): 5$.

34 Herwald H, Mörgelin M, Olsén A, Rhen M, Dahlbäck B, Müller-Esterl W, et al. Activation of the contact-phase system on bacterial surfaces - a clue to serious complications in infectious diseases. Nat Med. 1998 Mar;4(3): 298-302.

35 DeBenedictis EP, Liu J, Keten S. Adhesion mechanisms of curli subunit CsgA to abiotic surfaces. Sci Adv. 2016 Nov;2(11):e1600998.

36 Olsén A, Herwald H, Wikström M, Persson K, Mattsson E, Björck L. Identification of two protein-binding and functional regions of curli, a surface organelle and virulence determinant of Escherichia coli. J Biol Chem. 2002 Sep;277(37):34568-72.

37 Rochon M, Römling U. Flagellin in combination with curli fimbriae elicits an immune response in the gastrointestinal epithelial cell line HT-29. Microbes Infect. $2006 \mathrm{Jul} ; 8(8)$ : 2027-33.
38 Yi G, Brendel VP, Shu C, Li P, Palanathan S, Cheng Kao C. Single nucleotide polymorphisms of human STING can affect innate immune response to cyclic dinucleotides. PLoS One. 2013;8(10):e77846.

39 Ahmad I, Rouf SF, Sun L, Cimdins A, Shafeec S, Le Guyon S, et al. BcsZ inhibits biofilm phenotypes and promotes virulence by blocking cellulose production in Salmonella enterica serovar Typhimurium. Microb Cell Fact. 2016 Oct;15(1): 177.

40 Grantcharova N, Peters V, Monteiro C, Zakikhany K, Römling U. Bistable expression of CsgD in biofilm development of Salmonella enterica serovar Typhimurium. J Bacteriol. 2010 Jan;192(2):456-66.

41 Monteiro C, Saxena I, Wang X, Kader A, Bokranz W, Simm R, et al. Characterization of cellulose production in Escherichia coli Nissle 1917 and its biological consequences. Environ Microbiol. 2009 May;11(5):1105-16.

42 Ross P, Mayer R, Benziman M. Cellulose biosynthesis and function in bacteria. Microbiol Rev. 1991 Mar;55(1):35-58.

43 Seshasayee AS, Fraser GM, Luscombe NM. Comparative genomics of cyclic-di-GMP signalling in bacteria: post-translational regulation and catalytic activity. Nucleic Acids Res. 2010 Oct;38(18):5970-81.

44 Galperin MY. Diversity of structure and function of response regulator output domains. Curr Opin Microbiol. 2010 Apr;13(2):150-9.

45 Liu Y, Lee C, Li F, Trček J, Bähre H, Guo RT, et al. A cyclic di-GMP network is present in gram-positive Streptococcus and gram-negative Proteus species. ACS Infect Dis. 2020 Oct; 6(10):2672-87.

46 Simm R, Morr M, Kader A, Nimtz M, Römling U. GGDEF and EAL domains inversely regulate cyclic di-GMP levels and transition from sessility to motility. Mol Microbiol. 2004 Aug;53(4):1123-34.

47 Rossi E, Motta S, Aliverti A, Cossu F, Gourlay $\mathrm{L}$, Mauri P, et al. Cellulose production is coupled to sensing of the pyrimidine biosynthetic pathway via c-di-GMP production by the DgcQ protein of Escherichia coli. Environ Microbiol. 2017 Nov;19(11):4551-63.

48 Barends TR, Hartmann E, Griese JJ, Beitlich T, Kirienko NV, Ryjenkov DA, et al. Structure and mechanism of a bacterial light-regulated cyclic nucleotide phosphodiesterase. Nature. 2009 Jun;459(7249):1015-8.

49 Feirer N, Xu J, Allen KD, Koestler BJ, Bruger EL, Waters CM, et al. A pterin-dependent signaling pathway regulates a dual-function diguanylate cyclase-phosphodiesterase controlling surface attachment in Agrobacterium tumefaciens. MBio. 2015 Jun;6(4):e00156.

50 Hay ID, Remminghorst U, Rehm BH. MucR, a novel membrane-associated regulator of alginate biosynthesis in Pseudomonas aeruginosa. Appl Environ Microbiol. 2009 Feb; 75(4):1110-20.
51 Kader A, Simm R, Gerstel U, Morr M, Römling U. Hierarchical involvement of various GGDEF domain proteins in rdar morphotype development of Salmonella enterica serovar Typhimurium. Mol Microbiol. 2006 May; 60(3):602-16.

52 Ross P, Weinhouse H, Aloni Y, Michaeli D, Weinberger-Ohana P, Mayer R, et al. Regulation of cellulose synthesis in Acetobacter xylinum by cyclic diguanylic acid. Nature. 1987 Jan;325(6101):279-81.

53 Ryjenkov DA, Simm R, Römling U, Gomelsky $M$. The PilZ domain is a receptor for the second messenger c-di-GMP: the PilZ domain protein YcgR controls motility in enterobacteria. J Biol Chem. 2006 Oct;281(41):30310-4.

54 Krasteva PV, Sondermann H. Versatile modes of cellular regulation via cyclic dinucleotides. Nat Chem Biol. 2017 Mar;13(4): 350-9.

55 Nelson JW, Breaker RR. The lost language of the RNA World. Sci Signal. 2017 Jun;10(483): eaam8812.

56 Wang YC, Chin KH, Tu ZL, He J, Jones CJ, Sanchez DZ, et al. Nucleotide binding by the widespread high-affinity cyclic di-GMP receptor MshEN domain. Nat Commun. 2016 Aug;7:12481.

57 Claret L, Miquel S, Vieille N, Ryjenkov DA, Gomelsky M, Darfeuille-Michaud A. The flagellar sigma factor FliA regulates adhesion and invasion of Crohn disease-associated Escherichia coli via a cyclic dimeric GMP-dependent pathway. J Biol Chem. 2007 Nov; 282(46):33275-83

58 Bassis CM, Visick KL. The cyclic-di-GMP phosphodiesterase BinA negatively regulates cellulose-containing biofilms in Vibrio fischeri. J Bacteriol. 2010 Mar;192(5):1269-78.

59 Wang KC, Hsu YH, Huang YN, Yeh KS. A previously uncharacterized gene stm0551 plays a repressive role in the regulation of type 1 fimbriae in Salmonella enterica serotype Typhimurium. BMC Microbiol. 2012 Jun; 12: 111

60 Römling U, Amikam D. Cyclic di-GMP as a second messenger. Curr Opin Microbiol. 2006 Apr;9(2):218-28

61 Römling U, Gomelsky M, Galperin MY. C-diGMP: the dawning of a novel bacterial signalling system. Mol Microbiol. 2005 Aug;57(3): 629-39.

62 Tamayo R, Pratt JT, Camilli A. Roles of cyclic diguanylate in the regulation of bacterial pathogenesis. Annu Rev Microbiol. 2007;61: 131-48.

$63 \mathrm{Ng} \mathrm{CK}, \mathrm{Xu}$ J, Cai Z, Yang L, Thompson IP, Huang WE, et al. Elevated intracellular cyclicdi-GMP level in Shewanella oneidensis increases expression of c-type cytochromes. Microb Biotechnol. 2020 Nov;13(6):1904-16.

64 Fernandez NL, Srivastava D, Ngouajio AL, Waters CM. Cyclic di-GMP positively regulates DNA repair in Vibrio cholerae. J Bacteriol. 2018 Aug;200(15):e00005-18. 
65 Gibson DL, White AP, Snyder SD, Martin S, Heiss C, Azadi P, et al. Salmonella produces an $\mathrm{O}$-antigen capsule regulated by AgfD and important for environmental persistence. J Bacteriol. 2006 Nov; 188(22):7722-30.

66 Latasa C, Roux A, Toledo-Arana A, Ghigo JM, Gamazo C, Penadés JR, et al. BapA, a large secreted protein required for biofilm formation and host colonization of Salmonella enterica serovar Enteritidis. Mol Microbiol. 2005 Dec;58(5):1322-39.

67 Römling U. Characterization of the rdar morphotype, a multicellular behaviour in Enterobacteriaceae. Cell Mol Life Sci. 2005 Jun; 62(11):1234-46.

68 Tan MS, White AP, Rahman S, Dykes GA. Role of fimbriae, flagella and cellulose on the attachment of Salmonella Typhimurium ATCC 14028 to plant cell wall models. PLoS One. 2016;11(6): 0158311.

69 MacKenzie KD, Wang Y, Shivak DJ, Wong CS, Hoffman LJ, Lam S, et al. Bistable expression of CsgD in Salmonella enterica serovar Typhimurium connects virulence to persistence. Infect Immun. 2015 Jun;83(6):231226.

70 Huang Y, Leming CL, Suyemoto M, Altier C. Genome-wide screen of Salmonella genes expressed during infection in pigs, using in vivo expression technology. Appl Environ Microbiol. 2007 Dec;73(23):7522-30.

71 Ahmad I, Cimdins A, Beske T, Römling U. Detailed analysis of c-di-GMP mediated regulation of csgD expression in Salmonella Typhimurium. BMC Microbiol. 2017 Feb;17(1): 27.

72 Zakikhany K, Harrington CR, Nimtz M, Hinton JC, Römling U. Unphosphorylated CsgD controls biofilm formation in Salmonella enterica serovar Typhimurium. Mol Microbiol. 2010 Aug;77(3):771-86.

73 Karaolis DKR, Rashid MH, Chythanya R, Luo W, Hyodo M, Hayakawa Y. c-di-GMP (3'-5'-cyclic diguanylic acid) inhibits Staphylococcus aureus cell-cell interactions and biofilm formation. Antimicrob Agents Chemother. 2005 Mar;49(3):1029-38.

74 Korea CG, Badouraly R, Prevost MC, Ghigo JM, Beloin C. Escherichia coli K-12 possesses multiple cryptic but functional chaperone-usher fimbriae with distinct surface specificities. Environ Microbiol. 2010 Jul;12(7):1957-77.

75 Kolenda R, Ugorski M, Grzymajlo K. Everything you always wanted to know about Salmonella type 1 fimbriae, but were afraid to ask. Front Microbiol. 2019;10:1017.

76 Sterzenbach T, Nguyen KT, Nuccio SP, Winter MG, Vakulskas CA, Clegg S, et al. A novel CsrA titration mechanism regulates fimbrial gene expression in Salmonella Typhimurium. EMBO J. 2013 Oct;32(21):2872-83.

77 Monteiro C, Papenfort K, Hentrich K, Ahmad I, Le Guyon S, Reimann R, et al. Hfq and Hfqdependent small RNAs are major contributors to multicellular development in Salmonella enterica serovar Typhimurium. RNA Biol. 2012 Apr;9(4):489-502.
78 Vila J, Sáez-López E, Johnson JR, Römling U, Dobrindt U, Cantón R, et al. Escherichia coli: an old friend with new tidings. FEMS Microbiol Rev. 2016 Jul;40(4):437-63.

79 Cole SJ, Records AR, Orr MW, Linden SB, Lee VT. Catheter-associated urinary tract infection by Pseudomonas aeruginosa is mediated by exopolysaccharide-independent biofilms. Infect Immun. 2014 May;82(5):2048-58.

80 Wolfe AJ, Visick KL. Get the message out: cyclic-Di-GMP regulates multiple levels of flagellum-based motility. J Bacteriol. 2008 Jan; 190(2):463-75.

81 Purcell EB, Tamayo R. Cyclic diguanylate signaling in Gram-positive bacteria. FEMS Microbiol Rev. 2016 Sep;40(5):753-73.

82 Subramanian S, Kearns DB. Functional regulators of bacterial flagella. Annu Rev Microbiol. 2019 Sep;73:225-46.

83 Lamprokostopoulou A, Monteiro C, Rhen M, Römling U. Cyclic di-GMP signalling controls virulence properties of Salmonella enterica serovar Typhimurium at the mucosal lining. Environ Microbiol. 2010 Jan;12(1): 40-53.

84 Barak JD, Jahn CE, Gibson DL, Charkowski $\mathrm{AO}$. The role of cellulose and $\mathrm{O}$-antigen capsule in the colonization of plants by Salmonella enterica. Mol Plant Microbe Interact. 2007 Sep;20(9):1083-91.

85 Claret L, Miquel S, Vieille N, Ryjenkov DA, Gomelsky M, Darfeuille-Michaud A. The flagellar sigma factor FliA regulates adhesion and invasion of Crohn disease-associated Escherichia coli via a cyclic dimeric GMP-dependent pathway. J Biol Chem. 2007 Nov;282(46):33275-33283.

86 Hariharan VN, Yadav R, Thakur C, Singh A, Gopinathan R, Singh DP, et al. Cyclic di-GMP sensing histidine kinase PdtaS controls mycobacterial adaptation to carbon sources. FASEB J. 2021 Apr;35(4):e21475.

87 Ryan RP, Fouhy Y, Lucey JF, Jiang BL, He YQ, Feng JX, et al. Cyclic di-GMP signalling in the virulence and environmental adaptation of Xanthomonas campestris. Mol Microbiol. 2007 Jan;63(2):429-42.

88 Poudyal B, Sauer K. The PA3177 gene encodes an active diguanylate cyclase that contributes to biofilm antimicrobial tolerance but not biofilm formation by Pseudomonas aeruginosa. Antimicrob Agents Chemother. 2018 Oct;62(10):e01049-18.

89 Kim HK, Harshey RM. A diguanylate cyclase acts as a cell division inhibitor in a two-step response to reductive and envelope stresses. MBio. 2016 Aug;7(4):e00822-16.

90 Kulasakara H, Lee V, Brencic A, Liberati N, Urbach J, Miyata S, et al. Analysis of Pseudomonas aeruginosa diguanylate cyclases and phosphodiesterases reveals a role for bis-(3'5 ')-cyclic-GMP in virulence. Proc Natl Acad Sci U S A. 2006 Feb;103(8):2839-44.
91 Ahmad I, Lamprokostopoulou A, Le Guyon S, Streck E, Barthel M, Peters V, et al. Complex c-di-GMP signaling networks mediate transition between virulence properties and biofilm formation in Salmonella enterica serovar Typhimurium. PLoS One. 2011;6(12): e28351.

92 Simm R, Lusch A, Kader A, Andersson M, Römling U. Role of EAL-containing proteins in multicellular behavior of Salmonella enterica serovar Typhimurium. J Bacteriol. 2007 May; 189(9):3613-23.

93 Anwar N, Rouf SF, Römling U, Rhen M. Modulation of biofilm-formation in Salmonella enterica serovar Typhimurium by the periplasmic DsbA/DsbB oxidoreductase system requires the GGDEF-EAL domain protein STM3615. PLoS One. 2014;9(8): e106095.

94 MacKenzie KD, Wang Y, Musicha P, Hansen EG, Palmer MB, Herman DJ, et al. Parallel evolution leading to impaired biofilm formation in invasive Salmonella strains. PLoS Genet. 2019 Jun;15(6):e1008233.

95 Petersen E, Mills E, Miller SI. Cyclic-diGMP regulation promotes survival of a slow-replicating subpopulation of intracellular Salmonella Typhimurium. Proc Natl Acad Sci U S A. 2019 Mar;116(13):6335-40.

96 Pontes MH, Lee EJ, Choi J, Groisman EA. Salmonella promotes virulence by repressing cellulose production. Proc Natl Acad Sci U S A. 2015 Apr;112(16):5183-8.

97 Sokaribo AS, Balezantis LR, MacKenzie KD, Wang Y, Palmer MB, Chung B, et al. A SNP in the cache 1 signaling domain of diguanylate cyclase STM1987 leads to increased in vivo fitness of invasive Salmonella strains. Infect Immun. 2021 Mar;89(4):e00810-20.

98 Ledeboer NA, Frye JG, McClelland M, Jones BD. Salmonella enterica serovar Typhimurium requires the Lpf, Pef, and Tafi fimbriae for biofilm formation on HEp-2 tissue culture cells and chicken intestinal epithelium. Infect Immun. 2006 Jun;74(6):3156-69.

99 Ledeboer NA, Jones BD. Exopolysaccharide sugars contribute to biofilm formation by Salmonella enterica serovar Typhimurium on HEp-2 cells and chicken intestinal epithelium. J Bacteriol. 2005 May;187(9):321426.

100 Kai-Larsen Y, Lüthje P, Chromek M, Peters V, Wang X, Holm A, et al. Uropathogenic Escherichia coli modulates immune responses and its curli fimbriae interact with the antimicrobial peptide LL-37. PLoS Pathog. $2010 \mathrm{Jul} ; 6(7)$ :e1001010.

101 Gophna U, Barlev M, Seijffers R, Oelschlager TA, Hacker J, Ron EZ. Curli fibers mediate internalization of Escherichia coli by eukaryotic cells. Infect Immun. 2001 Apr;69(4): 2659-65.

102 Galán JE. Molecular genetic bases of Salmonella entry into host cells. Mol Microbiol. 1996 Apr;20(2):263-71. 
103 Solano C, García B, Valle J, Berasain C, Ghigo JM, Gamazo C, et al. Genetic analysis of Salmonella enteritidis biofilm formation: critical role of cellulose. Mol Microbiol. 2002 Feb;43(3):793-808.

104 Zorraquino V, García B, Latasa C, Echeverz M, Toledo-Arana A, Valle J, et al. Coordinated cyclic-di-GMP repression of Salmonella motility through YcgR and cellulose. J Bacteriol. 2013 Feb;195(3):417-28.

105 Tsolis RM, Young GM, Solnick JV, Bäumler AJ. From bench to bedside: stealth of enteroinvasive pathogens. Nat Rev Microbiol. 2008 Dec;6(12):883-92.

106 Steinberger O, Lapidot Z, Ben-Ishai Z, Amikam D. Elevated expression of the CD4 receptor and cell cycle arrest are induced in Jurkat cells by treatment with the novel cyclic dinucleotide 3',5'-cyclic diguanylic acid. FEBS Lett. 1999 Feb;444(1):125-9.

107 Ogunniyi AD, Paton JC, Kirby AC, McCullers JA, Cook J, Hyodo M, et al. c-di-GMP is an effective immunomodulator and vaccine adjuvant against pneumococcal infection. Vaccine. 2008 Aug;26(36):4676-85.

108 Martinez-Gil M, Ramos C. Role of cyclic diGMP in the bacterial virulence and evasion of the plant immunity. Curr Issues Mol Biol. 2018:25:199-222.

109 Cui T, Cang H, Yang B, He ZG. Cyclic dimeric guanosine monophosphate: activation and inhibition of innate immune response. J Innate Immun. 2019;11(3):242-8.

110 Karaolis DK, Newstead MW, Zeng X, Hyodo M, Hayakawa Y, Bhan U, et al. Cyclic diGMP stimulates protective innate immunity in bacterial pneumonia. Infect Immun. 2007 Oct;75(10):4942-50.

111 Fields PI, Swanson RV, Haidaris CG, Heffron F. Mutants of Salmonella Typhimurium that cannot survive within the macrophage are avirulent. Proc Natl Acad Sci U S A. 1986 Jul;83(14):5189-93.

112 Geddes K, Cruz F, Heffron F. Analysis of cells targeted by Salmonella type III secretion in vivo. PLoS Pathog. 2007 Dec;3(12): e196.

113 Jiang L, Wang P, Song X, Zhang H, Ma S, Wang J, et al. Salmonella Typhimurium reprograms macrophage metabolism via T3SS effector SopE2 to promote intracellular replication and virulence. Nat Commun. 2021 Feb;12(1):879.

114 Pulford CV, Perez-Sepulveda BM, Canals R, Bevington JA, Bengtsson RJ, Wenner N, et al. Stepwise evolution of Salmonella Typhimurium ST313 causing bloodstream infection in Africa. Nat Microbiol. 2021 Mar; 6(3):327-38

115 Singletary LA, Karlinsey JE, Libby SJ, Mooney JP, Lokken KL, Tsolis RM, et al. Loss of multicellular behavior in epidemic African nontyphoidal Salmonella enterica serovar Typhimurium ST313 strain D23580. MBio. 2016 Mar;7(2):e02265.
116 Petersen E, Miller SI. The cellular microbiology of Salmonellae interactions with macrophages. Cell Microbiol. 2019 Nov;21(11): e13116.

117 Ellermeier JR, Slauch JM. Adaptation to the host environment: regulation of the SPI1 type III secretion system in Salmonella enterica serovar Typhimurium. Curr Opin Microbiol. 2007 Feb;10(1):24-9.

118 Hansen-Wester I, Hensel M. Salmonella pathogenicity islands encoding type III secretion systems. Microbes Infect. 2001 Jun; 3(7):549-59.

119 Lostroh CP, Lee CA. The Salmonella pathogenicity island-1 type III secretion system. Microbes Infect. 2001;3(14-15):1281-91.

120 Desai SK, Winardhi RS, Periasamy S, Dykas MM, Jie Y, Kenney LJ. The horizontally-acquired response regulator SsrB drives a Salmonella lifestyle switch by relieving biofilm silencing. Elife. 2016 Feb;5:e10747.

121 Augustin DK, Song Y, Baek MS, Sawa Y, Singh G, Taylor B, et al. Presence or absence of lipopolysaccharide $\mathrm{O}$ antigens affects type III secretion by Pseudomonas aeruginosa. J Bacteriol. 2007 Mar;189(6):2203-9.

122 Pérez-Gutiérrez C, Llompart CM, Skurnik M, Bengoechea JA. Expression of the Yersinia enterocolitica $\mathrm{pYV}$-encoded type III secretion system is modulated by lipopolysaccharide $\mathrm{O}$-antigen status. Infect Immun. 2007 Mar;75(3):1512-6.

123 West NP, Sansonetti P, Mounier J, Exley RM, Parsot C, Guadagnini S, et al. Optimization of virulence functions through glucosylation of Shigella LPS. Science. $2005 \mathrm{Feb}$; 307(5713):1313-7.

124 Miyake M, Zhao L, Ezaki T, Hirose K, Khan $\mathrm{AQ}$, Kawamura $\mathrm{Y}$, et al. Vi-deficient and nonfimbriated mutants of Salmonella typhi agglutinate human blood type antigens and are hyperinvasive. FEMS Microbiol Lett. 1998 Apr;161(1):75-82.

125 House D, Bishop A, Parry C, Dougan G, Wain J. Typhoid fever: pathogenesis and disease. Curr Opin Infect Dis. 2001 Oct; 14(5):573-8

126 Prouty AM, Gunn JS. Comparative analysis of Salmonella enterica serovar Typhimurium biofilm formation on gallstones and on glass. Infect Immun. 2003 Dec;71(12):71548.

127 Yap MN, Yang CH, Barak JD, Jahn CE, Charkowski AO. The Erwinia chrysanthemi type III secretion system is required for multicellular behavior. J Bacteriol. 2005 Jan; 187(2):639-48.

128 Chevance FF, Hughes KT. Coordinating assembly of a bacterial macromolecular machine. Nat Rev Microbiol. 2008 Jun;6(6): 455-65.

129 Collazo CM, Galán JE. The invasion-associated type III system of Salmonella Typhimurium directs the translocation of Sip proteins into the host cell. Mol Microbiol. 1997 May;24(4):747-56.
130 Jennings E, Thurston TLM, Holden DW. Salmonella SPI-2 type III secretion system effectors: molecular mechanisms and physiological consequences. Cell Host Microbe. 2017 Aug;22(2):217-31.

131 Walthers D, Carroll RK, Navarre WW, Libby SJ, Fang FC, Kenney LJ. The response regulator SsrB activates expression of diverse Salmonella pathogenicity island 2 promoters and counters silencing by the nucleoidassociated protein H-NS. Mol Microbiol. 2007 Jul;65(2):477-93.

132 Desai SK, Padmanabhan A, Harshe S, Zaidel-Bar R, Kenney LJ. Salmonella biofilms program innate immunity for persistence in Caenorhabditis elegans. Proc Natl Acad Sci U S A. 2019 Jun;116(25):12462-7.

133 Echarren ML, Figueroa NR, Vitor-Horen L, Pucciarelli MG, García-Del Portillo F, Soncini FC. Balance between bacterial extracellular matrix production and intramacrophage proliferation by a Salmonella-specific SPI-2-encoded transcription factor. Mol Microbiol. 2021 Aug;116(4):1022-32.

134 Smith KD, Andersen-Nissen E, Hayashi F, Strobe K, Bergman MA, Barrett SL, et al. Toll-like receptor 5 recognizes a conserved site on flagellin required for protofilament formation and bacterial motility. Nat Immunol. 2003 Dec;4(12):1247-53.

135 Le Guyon S, Simm R, Rehn M, Römling U. Dissecting the cyclic di-guanylate monophosphate signalling network regulating motility in Salmonella enterica serovar Typhimurium. Environ Microbiol. 2015; 17(11):4818.

136 Vijay-Kumar M, Gewirtz AT. Role of flagellin in Crohn's disease: emblematic of the progress and enigmas in understanding inflammatory bowel disease. Inflamm Bowel Dis. 2009 May;15(5):789-95.

137 Hajam IA, Dar PA, Shahnawaz I, Jaume JC, Lee JH. Bacterial flagellin-a potent immunomodulatory agent. Exp Mol Med. 2017 Sep; 49(9):e373.

138 Pultz IS, Christen M, Kulasekara HD, Kennard A, Kulasekara B, Miller SI. The response threshold of Salmonella PilZ domain proteins is determined by their binding affinities for c-di-GMP. Mol Microbiol. 2012 Dec;86(6):1424-40.

139 Kumagai Y, Takeuchi O, Akira S. Pathogen recognition by innate receptors. J Infect Chemother. 2008 Apr;14(2):86-92.

140 Colaianni NR, Parys K, Lee HS, Conway JM, Kim NH, Edelbacher N, et al. A complex immune response to flagellin epitope variation in commensal communities. Cell Host Microbe. 2021 Apr;29(4):635-49.e9.

141 Cummings LA, Wilkerson WD, Bergsbaken $\mathrm{T}$, Cookson BT. In vivo, fliC expression by Salmonella enterica serovar Typhimurium is heterogeneous, regulated by ClpX, and anatomically restricted. Mol Microbiol. 2006 Aug;61(3):795-809. 
142 Miao EA, Andersen-Nissen E, Warren SE, Aderem A. TLR5 and Ipaf: dual sensors of bacterial flagellin in the innate immune system. Semin Immunopathol. 2007 Sep;29(3): 275-88.

143 Engl C, Waite CJ, McKenna JF, Bennett MH, Hamann T, Buck M. Chp8, a diguanylate cyclase from Pseudomonas syringae pv. Tomato DC3000, suppresses the pathogen-associated molecular pattern flagellin, increases extracellular polysaccharides, and promotes plant immune evasion. MBio. 2014 May; 5(3): e01168-14.

144 Pfeilmeier S, Saur IM, Rathjen JP, Zipfel C, Malone JG. High levels of cyclic-di-GMP in plant-associated Pseudomonas correlate with evasion of plant immunity. Mol Plant Pathol. 2016 May;17(4):521-31.

145 Simm R, Remminghorst U, Ahmad I, Zakikhany K, Römling U. A role for the EALlike protein STM1344 in regulation of CsgD expression and motility in Salmonella enterica serovar Typhimurium. J Bacteriol. 2009 Jun;191(12):3928-37.

146 Ahmad I, Wigren E, Le Guyon S, Vekkeli S, Blanka A, El Mouali Y, et al. The EAL-like protein STM1697 regulates virulence phenotypes, motility and biofilm formation in Salmonella typhimurium. Mol Microbiol. 2013 Dec;90(6):1216-32.

147 Wada T, Morizane T, Abo T, Tominaga A, Inoue-Tanaka K, Kutsukake K. EAL domain protein $\mathrm{YdiV}$ acts as an anti-FlhD4C2 factor responsible for nutritional control of the flagellar regulon in Salmonella enterica serovar Typhimurium. J Bacteriol. 2011 Apr;193(7): 1600-11.

148 Hisert KB, MacCoss M, Shiloh MU, Darwin $\mathrm{KH}$, Singh S, Jones RA, et al. A glutamatealanine-leucine (EAL) domain protein of Salmonella controls bacterial survival in mice, antioxidant defence and killing of macrophages: role of cyclic diGMP. Mol Microbiol. 2005 Jun;56(5):1234-45.

149 El Mouali Y, Kim H, Ahmad I, Brauner A, Liu Y, Skurnik M, et al. Stand-alone EAL domain proteins form a distinct subclass of EAL proteins involved in regulation of cell motility and biofilm formation in enterobacteria. J Bacteriol. 2017 Sep;199(18): e00179-17.

150 Furter M, Sellin ME, Hansson GC, Hardt WD. Mucus architecture and near-surface swimming affect distinct Salmonella Typhimurium infection patterns along the murine intestinal tract. Cell Rep. 2019 May; 27(9):2665-78.e3.

151 Ayabe T, Ashida T, Kohgo Y, Kono T. The role of Paneth cells and their antimicrobial peptides in innate host defense. Trends $\mathrm{Mi}-$ crobiol. 2004 Aug;12(8):394-8.

152 Johansson ME, Sjövall H, Hansson GC. The gastrointestinal mucus system in health and disease. Nat Rev Gastroenterol Hepatol. 2013 Jun;10(6):352-61.
153 Antelo GT, Vila AJ, Giedroc DP, Capdevila DA. Molecular evolution of transition metal bioavailability at the host-pathogen interface. Trends Microbiol. 2021 May;29(5): 441-57.

154 Golonka R, Yeoh BS, Vijay-Kumar M. The iron tug-of-war between bacterial siderophores and innate immunity. J Innate Immun. 2019;11(3):249-62.

155 Hurley BP, McCormick BA. Translating tissue culture results into animal models: the case of Salmonella Typhimurium. Trends Microbiol. 2003 Dec;11(12):562-9.

156 Asami J, Shimizu T. Structural and functional understanding of the toll-like receptors. Protein Sci. 2021 Apr;30(4):761-72.

157 Platnich JM, Muruve DA. NOD-like receptors and inflammasomes: a review of their canonical and non-canonical signaling pathways. Arch Biochem Biophys. 2019 Jul; 670:4-14.

158 Hevia A, Delgado S, Sánchez B, Margolles A. Molecular players involved in the interaction between beneficial bacteria and the immune system. Front Microbiol. 2015;6:1285.

159 Collier-Hyams LS, Neish AS. Innate immune relationship between commensal flora and the mammalian intestinal epithelium. Cell Mol Life Sci. 2005 Jun;62(12):1339-48.

160 Gewirtz AT, Yu Y, Krishna US, Israel DA, Lyons SL, Peek RM. Helicobacter pylori flagellin evades toll-like receptor 5-mediated innate immunity. J Infect Dis. 2004 May; 189(10):1914-20.

161 Amikam D, Steinberger O, Shkolnik T, BenIshai $\mathrm{Z}$. The novel cyclic dinucleotide 3'-5 cyclic diguanylic acid binds to p21ras and enhances DNA synthesis but not cell replication in the Molt 4 cell line. Biochem J. 1995 Nov;311 (Pt 3)(Pt 3):921-7.

162 Benner EJ, Mosley RL, Destache CJ, Lewis TB, Jackson-Lewis V, Gorantla S, et al. Therapeutic immunization protects dopaminergic neurons in a mouse model of Parkinson's disease. Proc Natl Acad Sci U S A. 2004 Jun 22;101(25):9435-40.

163 Nandakumar R, Tschismarov R, Meissner F, Prabakaran T, Krissanaprasit A, Farahani E, et al. Intracellular bacteria engage a STINGTBK1-MVB12b pathway to enable paracrine cGAS-STING signalling. Nat Microbiol. 2019 Apr;4(4):701-13.

164 Ablasser A, Goldeck M, Cavlar T, Deimling T, Witte G, Röhl I, et al. cGAS produces a 2'-5'-linked cyclic dinucleotide second messenger that activates STING. Nature. 2013 Jun;498(7454):380-4.

165 Burdette DL, Monroe KM, Sotelo-Troha K, Iwig JS, Eckert B, Hyodo M, et al. STING is a direct innate immune sensor of cyclic diGMP. Nature. 2011 Sep;478(7370):515-8.

166 Park SM, Omatsu T, Zhao Y, Yoshida N, Shah $\mathrm{P}$, Zagani R, et al. T cell fate following Salmonella infection is determined by a STING-IRF1 signaling axis in mice. Commun Biol. 2019;2:464.
167 Shmuel-Galia L, Humphries F, Lei X, Ceglia $\mathrm{S}$, Wilson R, Jiang Z, et al. Dysbiosis exacerbates colitis by promoting ubiquitination and accumulation of the innate immune adaptor STING in myeloid cells. Immunity. 2021 Jun;54(6):1137-53.e8.

168 Li W, Cui T, Hu L, Wang Z, Li Z, He ZG. Cyclic diguanylate monophosphate directly binds to human siderocalin and inhibits its antibacterial activity. Nat Commun. 2015 Sep;6:8330.

169 Woodward JJ, Iavarone AT, Portnoy DA. cdi-AMP secreted by intracellular Listeria monocytogenes activates a host type I interferon response. Science. 2010 Jun;328(5986): 1703-5.

170 White AP, Gibson DL, Grassl GA, Kay WW, Finlay BB, Vallance BA, et al. Aggregation via the red, dry, and rough morphotype is not a virulence adaptation in Salmonella enterica serovar Typhimurium. Infect Immun. 2008 Mar;76(3):1048-58

171 Simm R, Ahmad I, Rhen M, Le Guyon S, Römling U. Regulation of biofilm formation in Salmonella enterica serovar Typhimurium. Future Microbiol. 2014;9(11):1261-82.

172 Humphries A, Deridder S, Bäumler AJ. Salmonella enterica serotype Typhimurium fimbrial proteins serve as antigens during infection of mice. Infect Immun. 2005 Sep; 73(9):5329-38.

173 Miller AL, Pasternak JA, Medeiros NJ, Nicastro LK, Tursi SA, Hansen EG, et al. In vivo synthesis of bacterial amyloid curli contributes to joint inflammation during $S$. Typhimurium infection. PLoS Pathog. 2020 Jul;16(7):e1008591.

174 Silva AJ, Benitez JA. Vibrio cholerae biofilms and cholera pathogenesis. PLoS Negl Trop Dis. 2016 Feb; 10(2):e0004330.

175 Alteri CJ, Xicohténcatl-Cortes J, Hess S, Caballero-Olín G, Girón JA, Friedman RL. Mycobacterium tuberculosis produces pili during human infection. Proc Natl Acad Sci U S A. 2007 Mar; 104(12):5145-50.

176 Haneda T, Winter SE, Butler BP, Wilson RP, Tükel C, Winter MG, et al. The capsule-encoding viaB locus reduces intestinal inflammation by a Salmonella pathogenicity island 1-independent mechanism. Infect Immun. 2009 Jul;77(7):2932-42.

177 Rapsinski GJ, Newman TN, Oppong GO van Putten JP, Tükel CC. CD14 protein acts as an adaptor molecule for the immune recognition of Salmonella curli fibers. J Biol Chem. 2013 May;288(20):14178-88.

178 Tükel C, Nishimori JH, Wilson RP, Winter MG, Keestra AM, van Putten JP, et al. Tolllike receptors 1 and 2 cooperatively mediate immune responses to curli, a common amyloid from enterobacterial biofilms. Cell Microbiol. 2010 Oct;12(10):1495-505.

179 Kawai T, Akira S. The roles of TLRs, RLRs and NLRs in pathogen recognition. Int Immunol. 2009 Apr;21(4):317-37. 
180 Oppong GO, Rapsinski GJ, Tursi SA, Biesecker SG, Klein-Szanto AJ, Goulian M, et al. Biofilm-associated bacterial amyloids dampen inflammation in the gut: oral treatment with curli fibres reduces the severity of hapten-induced colitis in mice. NPJ Biofilms Microbiomes. 2015;1:15019.

181 Oppong GO, Rapsinski GJ, Newman TN, Nishimori JH, Biesecker SG, Tükel Ç. Epithelial cells augment barrier function via activation of the Toll-like receptor 2/ phosphatidylinositol 3-kinase pathway upon recognition of Salmonella enterica serovar Typhimurium curli fibrils in the gut. Infect Immun. $2013 \mathrm{Feb} ; 81(2)$ :47886.

182 Tursi SA, Lee EY, Medeiros NJ, Lee MH, Nicastro LK, Buttaro B, et al. Bacterial amy- loid curli acts as a carrier for DNA to elicit an autoimmune response via TLR2 and TLR9. PLoS Pathog. 2017 Apr;13(4): e1006315.

183 Gallo PM, Rapsinski GJ, Wilson RP, Oppong GO, Sriram U, Goulian M, et al. Amyloid-DNA composites of bacterial biofilms stimulate autoimmunity. Immunity. 2015 Jun 16;42(6):1171-84.

184 Sampson TR, Challis C, Jain N, Moiseyenko A, Ladinsky MS, Shastri GG, et al. A gut bacterial amyloid promotes a-synuclein aggregation and motor impairment in mice. Elife. 2020;9:e53111.

185 Bian Z, Yan ZQ, Hansson GK, Thorén P, Normark S. Activation of inducible nitric oxide synthase/nitric oxide by curli fibers leads to a fall in blood pressure during sys- temic Escherichia coli infection in mice. J Infect Dis. 2001 Feb;183(4):612-9.

186 Wang D, Ding X, Rather PN. Indole can act as an extracellular signal in Escherichia coli. J Bacteriol. 2001 Jul;183(14):4210-6.

187 Elmanfi S, Zhou J, Sintim HO, Könönen E, Gürsoy M, Gürsoy UK. Regulation of gingival epithelial cytokine response by bacterial cyclic dinucleotides. J Oral Microbiol. 2019; 11(1):1538927.

188 Gao J, Tao J, Liang W, Jiang Z. Cyclic (di) nucleotides: the common language shared by microbe and host. Curr Opin Microbiol. 2016 Apr;30:79-87.

189 Kim CC, Falkow S. Delineation of upstream signaling events in the salmonella pathogenicity island 2 transcriptional activation pathway. J Bacteriol. 2004 Jul;186(14):4694-704. 